\title{
Developing and bounding ice particle mass- and area-dimension expressions for use in atmospheric models and remote sensing
}

\author{
Ehsan Erfani ${ }^{1,2}$ and David L. Mitchell ${ }^{1}$ \\ ${ }^{1}$ Desert Research Institute, Reno, Nevada, USA \\ ${ }^{2}$ Graduate Program in Atmospheric Sciences, University of Nevada, Reno, Nevada, USA \\ Correspondence to: Ehsan Erfani (ehsan@nevada.unr.edu)
}

Received: 21 September 2015 - Published in Atmos. Chem. Phys. Discuss.: 22 October 2015

Revised: 9 March 2016 - Accepted: 29 March 2016 - Published: 7 April 2016

\begin{abstract}
Ice particle mass- and projected area-dimension ( $m-D$ and $A-D$ ) power laws are commonly used in the treatment of ice cloud microphysical and optical properties and the remote sensing of ice cloud properties. Although there has long been evidence that a single $m-D$ or $A-D$ power law is often not valid over all ice particle sizes, few studies have addressed this fact. This study develops self-consistent $m-D$ and $A-D$ expressions that are not power laws but can easily be reduced to power laws for the ice particle size (maximum dimension or $D$ ) range of interest, and they are valid over a much larger $D$ range than power laws. This was done by combining ground measurements of individual ice particle $m$ and $D$ formed at temperature $T<-20^{\circ} \mathrm{C}$ during a cloud seeding field campaign with 2-D stereo (2D-S) and cloud particle imager (CPI) probe measurements of $D$ and $A$, and estimates of $m$, in synoptic and anvil ice clouds at similar temperatures. The resulting $m-D$ and $A-D$ expressions are functions of temperature and cloud type (synoptic vs. anvil), and are in good agreement with $m-D$ power laws developed from recent field studies considering the same temperature range $\left(-60^{\circ} \mathrm{C}<T<-20^{\circ} \mathrm{C}\right)$.
\end{abstract}

\section{Introduction}

Measurements of individual ice particle mass have shown that the relationships between ice particle mass and maximum dimension have the form of habit-dependent power laws (Locatelli and Hobbs, 1974; Mitchell et al., 1990; hereafter M1990). The treatment of ice particle projected area and mass is fundamental for the prediction of ice cloud microphysical and radiative properties in cloud models at all scales. For example, Mitchell (1988) showed how treating ice particles as spheres in a steady-state snow growth model resulted in poor agreement between the observed and model predicted height-dependent evolution of ice particle size distributions (PSDs), relative to PSDs predicted using a non-Euclidian ice particle mass-dimension (henceforth $m$ $D$, where $D$ is maximum dimension) power law relationship. Moreover, ice particle $m-D$ and projected area-dimension (henceforth $A-D$ ) relationships are used to predict ice particle fall velocities (e.g., Mitchell, 1996; Heymsfield and Westbrook, 2010). Ice cloud optical properties have also been formulated in terms of ice particle $m-D$ and $A-D$ power laws, as described in Mitchell $(1996,2000,2002)$ and Mitchell et al. (2006). The ice PSD effective diameter $\left(D_{\mathrm{e}}\right)$, used in other ice optical property schemes (e.g., Fu, 1996; Fu et al., 1998; Yang et al., 2005), is also based on the ratio of PSD mass to PSD projected area (e.g., Foot, 1988; Mitchell, 2002). From this, it is apparent that $m-D$ and $A-D$ expressions have the potential to integrate microphysical and radiative processes in cloud models in a self-consistent manner.

In addition to the treatment of microphysical and radiative processes in cloud models, $m-D$ and $A-D$ expressions constitute critical a priori information used to retrieve cloud properties in ground- and satellite-based remote sensing. For example, uncertainties (standard deviations or $\sigma$ ) associated with $m-D$ and $A-D$ expressions strongly contribute to uncertainties in $D_{\mathrm{e}}$ and ice water content (IWC) retrievals that range from 60 to $68 \%$ and from 135 to $175 \%$, respectively, relative to their mean values (Zhao et al., 2011). Reducing the uncertainty of $m-D$ and $A-D$ expressions would reduce the uncertainties associated with these and other cloud property retrievals. 
Research over the last decade has used aircraft measurements of bulk IWC and the ice PSD to develop best estimates of the $m-D$ power law relationship (e.g., Heymsfield et al., 2004, 2007, 2010; hereafter H2010). Also, McFarquhar et al. (2007) used PSDs and radar reflectivities measured during spiral descents in the stratiform regions of mesoscale convective systems to determine the power law for each spiral. In addition, the recent study by Fontaine et al. (2014) employed ice particle images and radar reflectivities to derive the temperature-dependent power exponent and prefactor of power laws for tropical anvil clouds. However, these approaches implicitly assume that the $m$ $D$ relationship conforms to a single size-independent power law, whereas Table 1 in Mitchell (1996) indicates that it often takes two or even three $m-D$ power laws to describe a given $m-D$ relationship over all relevant sizes. For example, Mitchell (1996) determined three power laws for hexagonal columns for three size ranges: $30 \mu \mathrm{m}<D \leq 100 \mu \mathrm{m}$, $100 \mu \mathrm{m}<D \leq 300 \mu \mathrm{m}$, and $D>300 \mu \mathrm{m}$. Cotton et al. (2013; hereafter C2013) have developed a bulk IWC approach that yields two $m$ - $D$ power laws that better describe the observations, assuming an exponent of 3 for the smallest ice particle sizes $(D<70 \mu \mathrm{m})$. These $m-D$ relationships consisting of two or three power laws are shown in Fig. 1, where it is seen that the dependence of $m$ on $D$ in log-log space is non-linear. Note that the C2013 relationship is based on all ice particle shapes present at the time of sampling, whereas four relationships are for specific ice crystal habits, based on Table 1 in Mitchell (1996). The popular Brown and Francis (1995) $m$ - $D$ power law, also based on all ice particle shapes present at the time of sampling, is also shown in Fig. 1, where it exceeds the mass of an ice sphere (the upper mass limit) when $D<97 \mu \mathrm{m}$. Many investigators have assumed ice spheres for $D<97 \mu \mathrm{m}$ when applying the Brown-Francis relationship, but this may introduce some error based on the findings of C2013. Clearly, the Brown-Francis relationship is not valid over all sizes and two $m$ - $D$ relationships are needed to address the smaller sizes. In summary, these relationships imply that the $m-D$ relationship has some curvature in log-log space and a key objective of this study is to parameterize this curvature for a mixture of ice particle shapes commonly found in ice clouds.

Another main objective of this study is to provide the climate modeling and the ice cloud remote sensing community with a method for calculating representative ice particle masses and projected areas in ice clouds at sizes relevant to cirrus clouds in terms of temperature regime and cloud type (synoptic vs. anvil cirrus), including uncertainty estimates. To date, no direct measurements of individual ice particle masses have been made from an aircraft, so direct in situ measurements of size-resolved ice particle mass and dimension are not available. Given this limitation, a system is developed that attempts to make optimal use of the measurements that currently exist. Thus, this study is proposing not

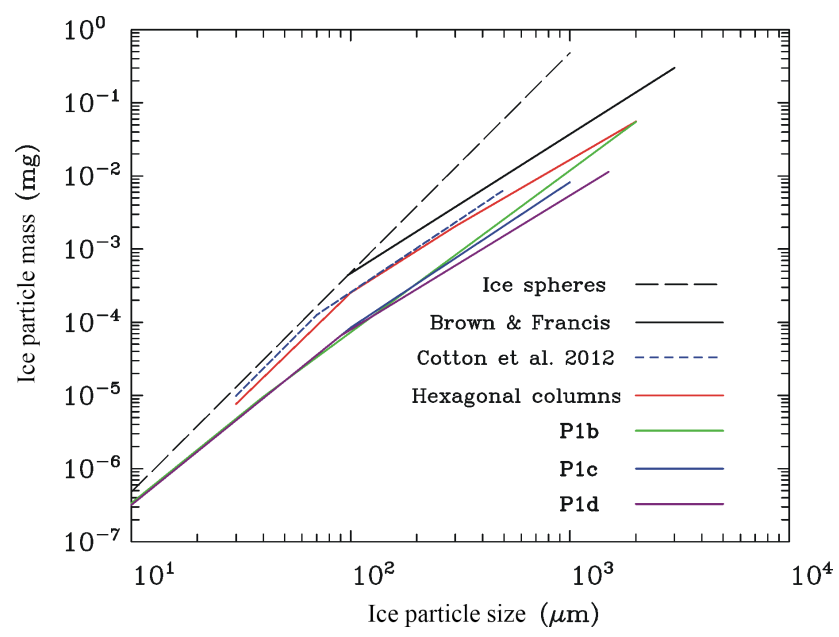

Figure 1. Dependence of ice particle mass $(m)$ on ice particle maximum dimension $(D)$, based on a variety of power law relationships in the literature (see text for details). Ice spheres indicate an upper limit for $m$ at a given $D$. P1b, P1c, and P1d denote planar crystals with sector-like branches, broad branches, and stellar dendrites, respectively, as described in Mitchell (1996).

a solution to this problem but rather an improvement for describing the $m-D$ and $A-D$ relationships in cirrus clouds.

Section 2 of this study discusses the data and method, with the first subsection providing a brief overview of the general approach adopted for estimating $m-D$ expressions in cirrus clouds and the other subsections explaining groundbased measurements of individual ice particle masses and various aircraft in situ measurements and their processing methods. Sections 3 and 4 then provide more details, with Sect. 3 describing how aircraft and ground-based measurements were used to develop $m-D$ and $A-D$ relationships. In Sect. 4, the aircraft results are compared against the results from a cloud seeding program called the Sierra Cooperative Pilot Project (SCPP), described in M1990. In Sect. 5, a method for reducing these $m-D$ and $A-D$ expressions into $m-D$ and $A-D$ power law relationships over a limited size range is described, along with uncertainty estimates for the prefactor and exponent of these power law expressions. Section 6 provides a method for applying the polynomial fits to two-moment cloud microphysical schemes where an appropriate power law expression (derived from a polynomial fit) can be applied over the ice particle size range of interest. This section also describes the impact this scheme is likely to have on ice microphysical schemes that assume that ice particles are spherical. Summary and concluding remarks are given in Sect. 7. 


\section{Data and methods}

\subsection{Parameterization approach - general description}

To address the challenges described above, a non-standard approach was taken that combines aircraft measurements and estimates of ice particle projected area and mass, respectively, with single ice particle field measurements of mass and maximum dimension. The aircraft measurements were made during the Small Particle In Cirrus (SPARTICUS) field campaign (Mace et al., 2009), funded through the Atmospheric Systems Research (ASR) program by the Department of Energy (DOE), which took place during JanuaryJune 2010 over the continental USA (see Fig. 2 in Mishra et al., 2014, for the map of flight locations), from which 13 synoptic cirrus flights and 9 anvil cirrus flights were selected; these are listed in Table 1 of Mishra et al. (2014). The 2-D stereo (2D-S) probe (Lawson et al., 2006a; Lawson, 2011) and cloud particle imager (CPI) probe (Lawson et al., 2001) were on board the aircraft, and were used in this study for the PSD measurements. In general, ice particle mass is estimated from the SPARTICUS measurements of ice particle projected area, as described in more detail below, giving an ice particle size range appropriate for ice clouds colder than about $-20^{\circ} \mathrm{C}$. Ground-based measurements of $m$ and $D$ from SCPP corresponding to ice crystals that formed between -20 and $-40^{\circ} \mathrm{C}$ are then compared with the 2D-S estimates of $m$ and $D$ sampled between -20 and $-40^{\circ} \mathrm{C}$, and are found to be in relatively good agreement as discussed in Sect. 3. Due to this agreement, we postulate that the $m-D$ expression derived from the $2 \mathrm{D}-\mathrm{S}$ probe data should be reasonable over this temperature range. We further postulate that ice particle mass estimates at colder temperatures, based on 2D$S$ probe ice particle projected area measurements, should be reasonable provided that the ice particle shape composition of the PSD does not significantly change at these colder temperatures. Moreover, we assume that a similar shape composition for anvil cirrus for a given temperature range relative to the shape composition in synoptic cirrus from -40 to $-20^{\circ} \mathrm{C}$ justifies using the $2 \mathrm{D}-\mathrm{S}$ probe mass estimates (based on area measurements) for these anvil cirrus. As a proxy for ice particle shape, we use the mean area ratio $\left(A_{\mathrm{r}}\right)$ for a given ice particle size bin, where the $A_{\mathrm{r}}$ is the measured particle area divided by area of the circle defined by the particle's maximum dimension. This assumption extends this $m-D$ parameterization down to $-55^{\circ} \mathrm{C}$. More details about this approach will now be given.

SCPP (see Sect. 2.2) provides unique direct measurements of mass for ice particles, with many SCPP ice particles having ice particle shapes similar to those found in cirrus clouds. Therefore, we used this data subset for size greater than $100 \mu \mathrm{m}$ and CPI data (see Sect. 2.4) for size between 20 and $100 \mu \mathrm{m}$. Only those SCPP ice particles having formation temperatures between -20 and $-40^{\circ} \mathrm{C}$ (based on observed habits) were selected. For other temperature ranges

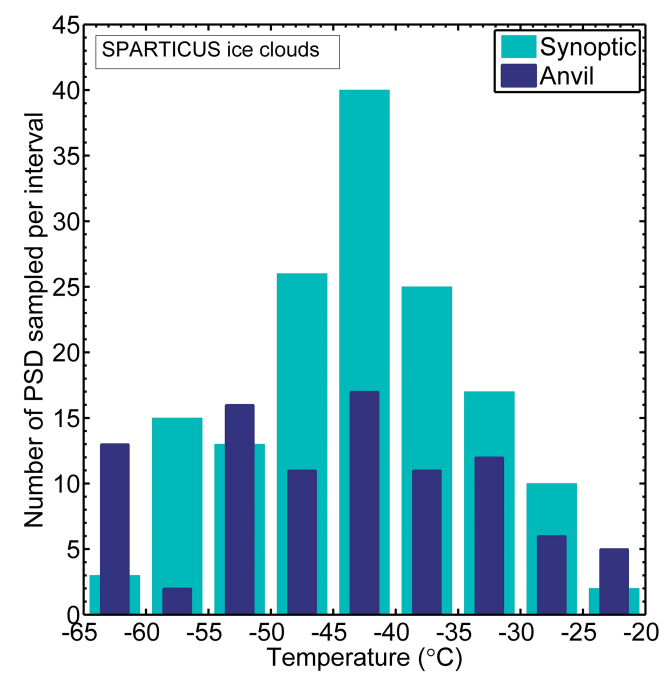

Figure 2. SPARTICUS PSD sampling statistics for synoptic and anvil cirrus clouds where the PSDs have been grouped into temperature intervals of $5^{\circ} \mathrm{C}$.

of synoptic clouds and for all temperature ranges of anvil clouds, estimated 2D-S mass (see Sect. 2.3) is used for size greater than $200 \mu \mathrm{m}$ and estimated CPI mass (see Sect. 2.4 and Appendix B) for size less than $100 \mu \mathrm{m}$. Since direct measurement of projected area is available for both $2 \mathrm{D}-\mathrm{S}$ and CPI data, 2D-S area is used for size greater than $200 \mu \mathrm{m}$ and CPI area is used for size less than $200 \mu \mathrm{m}$ for all temperature ranges. Additional details are given below.

\subsection{SCPP measurements}

SCPP was a 3-year field study on cloud seeding funded by the Bureau of Reclamation, and for one part of that project the shapes, maximum dimensions, and masses of 4869 ice particles were determined. As described in M1990, ice particles were collected during winter storms in a petri dish and then imaged under a microscope equipped with a camera. The maximum dimension of each ice particle (i.e., diameter of a circumscribed circle around the particle) was later measured in the lab. In addition, each ice particle was melted with a heat lamp under the microscope, with a corresponding photo taken immediately after melting. This resulted in hemispheric water drops that were imaged in the lab to measure the diameter of the hemispheres and from that the volume and mass of each ice particle was calculated. Although shattering can affect the aircraft measurements of ice particles due to the high sampling speed, it has no significant effect on the ground-based measurements. Moreover, the smallest size that is measured during SCPP $(\sim 150 \mu \mathrm{m})$ is considerably larger than the size range of shattered ice artifacts ( $D<50 \mu \mathrm{m}$; Jackson et al., 2012). Therefore, shattering during the SCPP measurements is not a concern. While greater magnification was used to photograph the ice particles during the last year, for purposes of measuring ice particle size 
and mass, the lower magnification $(25 \times)$ was sufficient. In this study, we consider those ice particles measured during the SCPP that have shapes initially formed between -20 and $-40^{\circ} \mathrm{C}$. Moreover, the objective of M1990 was to develop $m-D$ power laws for specific ice particle habits or shape categories (e.g., rimed column aggregates), whereas the objective of this study is to develop $m-D$ and $A-D$ expressions that are representative of all ice particles for a given cloud type and temperature interval, suitable for use in climate models (see Sect. 3 for the discussion of variability in $m-D$ and $A-D$ expressions).

Such field observations, conducted during winter storms in the Sierra Nevada Mountains, provided measurements for each individual ice particle sampled, including date and time, maximum dimension, mass, shape (if identifiable), crude level of riming (light, moderate, heavily rimed, or graupel), and temperature range that produces the observed ice particle shape. Software was created to extract any combination of ice particle shapes. For the winter storms sampled, most of the cold-habit ice crystals are expected to originate between -20 and $-40^{\circ} \mathrm{C}$, although cloud tops colder than $-40^{\circ} \mathrm{C}$ are possible. Ice particle shapes associated with $T<-20^{\circ} \mathrm{C}$ that were measured during this field study include short columns (aspect ratios were $<2$ ) and combinations thereof, side planes and their aggregates, bullets, bullet rosettes and aggregates thereof, and combinations of any of these crystal types.

\subsection{D-S probe}

PSDs were sampled using the 2D-S probe, which measures the size-resolved concentrations of ice particle number and projected area. A total of 193 synoptic ice cloud PSDs and 115 anvil cirrus PSDs were sampled and analyzed. Ice particle concentrations were measured down to $10 \mu \mathrm{m}(5-15 \mu \mathrm{m}$ size bin) and up to $1280 \mu \mathrm{m}$ in ice particle length. The data in the smallest size bin $(5-15 \mu \mathrm{m})$ should be used with caution, because Jensen et al. (2013) showed that the largest uncertainty in depth of field for this size bin results in an overestimation of number concentration for particles in the smallest size bin. Since we used CPI data for the size range smaller than $100 \mu \mathrm{m}$, the aforementioned problem does not affect the calculations of $m-D$ and $A-D$ relationships. Ice particle mass is not directly measured but is estimated using a power law that relates ice particle projected area to mass (Baker and Lawson, 2006a; hereafter BL2006). This relationship was developed from a subset of ice particles (865 particles) measured during SCPP. Using image analysis software, the projected area of ice particles in this subset was calculated from their photographed magnified images. The BL2006 study found that ice particle projected area was a more reliable predictor of particle mass than was maximum dimension. Their $m-A$ power law was derived from many types of ice particle habits or shapes; of the 550 identifiable ice particles, $36 \%$ were moderately or heavily rimed. This $m-A$ power law is now commonly used to estimate size-resolved mass concentrations from 2D-S probe measurements of projected area. Integrating these mass concentrations over the PSD, the PSD IWC is determined.

IWCs based on BL2006, determined by integration over PSDs, have been compared to IWCs directly measured by the counterflow virtual impactor (CVI) probe during the Tropical Composition, Cloud and Climate Coupling (TC4) field campaign (Lawson et al., 2010), where the 2D-S and CVI probes were co-located on the same aircraft with identical sampling times. A regression line relating the 2D-S and CVI IWC measurements had a coefficient of determination $\left(R^{2}\right)$ of 0.88 , with $2 \mathrm{D}$-S IWCs being $82 \%$ of CVI IWCs on average.

The methodology for extracting $m-D$ expressions from 2D-S probe data was first described in Mitchell et al. (2011) and is briefly described here. The mean ice particle mass is calculated for each size bin of the 2D-S probe by dividing the mass concentration in the bin by the measured number concentration $(N)$ in the bin. In this way the mean bin mass is related to bin midpoint size for each size bin of the 2D-S probe. The relationship between $m$ and $D$ can then be characterized by plotting mean bin mass against bin midpoint size and fitting the data to an equation of $m$ and $D$. This was done for the SPARTICUS 2D-S data as described below.

The processing of the 2D-S probe SPARTICUS data is described in Mishra et al. (2014). The original 2D-S data used in this study had been processed by the Stratton Park Engineering Company (SPEC) Inc. using the M1 technique for measuring ice particle length and area (see Appendix A in Lawson, 2011). However, the M1 method does not ensure that the ice particle is completely imaged within the sample volume (i.e., that no portion is beyond the photodiode array), and it uses the length parameter along the direction of travel (L1; see Appendix A) for maximum dimension. To overcome these drawbacks, the 2D-S data used here were processed using the newly developed M7 method that insures that the ice particles are completely imaged within the sample volume ("all-in" criteria), and this method uses the most accurate estimate for maximum dimension (diameter of circumscribed circle around the particle; see Appendix A). Although the sample volume decreases by using the M7 method, such a decrease is not significant. It is shown in the supplement (Figs. S1 and S3 in the Supplement) that the M1 and M7 methods agree well for both number concentration and area concentration, with the largest difference between the M1 and M7 methods observed for larger particles $(D>300 \mu \mathrm{m})$. Moreover, the difference in PSD projected area (i.e., extinction) between the M1 and M7 methods does not exceed 5 and $13 \%$ for synoptic and anvil cirrus clouds, respectively (Figs. S2 and S4; see Appendix A for a detailed discussion on the comparison between M1 and M7 methods). The 2D$\mathrm{S}$ data were then further processed to insure that ice particle mass and projected area did not exceed that of an ice sphere 
having a diameter equal to the ice particle maximum dimension.

PSDs for each cloud type (synoptic or anvil) were partitioned into temperature intervals of $5^{\circ} \mathrm{C}$ and the PSDs within each temperature interval were averaged to produce nine mean PSDs (one for each $T$ interval) for synoptic and nine mean PSDs for anvil ice clouds. This covered a temperature range of -20 to $-65^{\circ} \mathrm{C}$ for both synoptic and anvil ice clouds.

While ice clouds at temperatures warmer than $-38^{\circ} \mathrm{C}$ might be mixed phase (containing both liquid water and ice), all PSDs were examined for the presence of liquid water using a combination of forward scattering spectrometer probe (FSSP), CPI and 2D-S probes, and relative humidity measurements using the diode laser hygrometer (DLH) probe. Only PSDs not associated with evidence of liquid water were used in this analysis as described in Mishra et al. (2014). Moreover, the PSD selection process identified cloud regions (cloud extinction $>0.1 \mathrm{~km}^{-1}$ ) where cloud extinction and median mass size were relatively stable (i.e., in a $60 \mathrm{~s}$ time period, the cloud extinction and median mass size should not exceed 2 times their mean and should not be less than 0.4 times their mean), making it unlikely that liquid water was present. However, it is possible that some ice particles sampled were rimed if riming occurred at levels above the level being sampled (considered unlikely for these temperatures). The number of PSDs found in each temperature interval is shown for synoptic and anvil ice clouds in Fig. 2.

There is an out-of-focus problem affecting the 2D-S measurements of projected area, specifically for ice particle sizes less than $200 \mu \mathrm{m}$. For this size range, many images are out of focus with artificial holes in the middle, so that particles have an appearance similar to doughnuts, and the projected area of these images is overestimated (Korolev, 2007). Therefore, we used the 2D-S M7 projected area for ice particle sizes larger than $200 \mu \mathrm{m}$, and the CPI projected area for sizes smaller than $200 \mu \mathrm{m}$ (see next subsection).

\subsection{CPI probe}

The CPI probe provides digital images of particles that pass through the sample volume at speeds up to $200 \mathrm{~m} \mathrm{~s}^{-1}$. The images were processed via CPIview software to determine ice particle length, width, projected area, perimeter, and crystal habits, with the resolution of $2.3 \mu \mathrm{m}$, and for particles in the size range of 10-2000 $\mu \mathrm{m}$ (Lawson et al., 2001). The majority of the CPI images are in focus, and a few of them that are out of focus are resized smaller using Korolev focus correction (Korolev et al., 1998). For this reason, CPI projected area is more reliable compared to the $2 \mathrm{D}-\mathrm{S}$ for ice particle size less than $200 \mu \mathrm{m}$ and we used CPI projected area for sizes less than $200 \mu \mathrm{m}$. A discontinuity in projected area is observed between the $2 \mathrm{D}-\mathrm{S}$ using $\mathrm{M} 1$ processing and the CPI for $D \approx 200 \mu \mathrm{m}$, with $2 \mathrm{D}-\mathrm{S}$ area being larger than CPI area by a factor of $1.54 \pm 0.18$. There are three factors that con- tribute to this discrepancy: first, 2D-S M1 for larger sizes can still be out of focus, though less than that for smaller sizes; second, it seems that $2 \mathrm{D}-\mathrm{S}$ overestimates size with errors being 10-30\%, even when they are in focus; third, there are inherent differences between CPI and 2D-S, since they are two different instruments that use two different measurement techniques. Using the M7 data processing, the 2D-S area is larger than CPI area by a factor of $1.30 \pm 0.15$, showing that M7 and CPI are more self-consistent than M1 and CPI. The number of ice particles imaged by the CPI that were used in this study is 224719 . Hence, the CPI sampling statistics in each size bin is quite good.

The CPI probe does not measure ice particle mass and the BL2006 $m$ - $A$ method is not justified for sizes smaller than $150 \mu \mathrm{m}$ because it was derived from a subset of SCPP data with ice particles having sizes greater than $\sim 150 \mu \mathrm{m}$. Therefore, we developed a methodology (see Appendix B) to estimate mass from the CPI measurements of projected area and aspect ratio. This new methodology assumes that ice particles with size less than $100 \mu \mathrm{m}$ exhibit hexagonal column geometry. Such a geometrical assumption seems reasonable based on observations for sizes smaller than $100 \mu \mathrm{m}$ (see Lawson et al., 2006a, their Figs. 4 and 5). While other authors have approximated small (e.g., $D<50 \mu \mathrm{m}$ ) ice crystals as "droxtals", Gaussian random spheres, Chebyshev particles, and budding bucky balls (e.g., Um and McFarquhar, 2011), our study estimates the mass of small ice particles from processed CPI data that contain measurements of ice particle projected area, length, and width. We developed a method that utilizes all three of these properties to estimate ice particle mass. For the size range we considered (20 to $100 \mu \mathrm{m})$, the mean length-to-width ratio was $1.41 \pm 0.26$, confirming the dominance of high-density ice particles, and, for such aspect ratios, hexagonal columns appear to be as good a surrogate of small particle morphology as the other shapes noted above for estimating ice particle mass. They also provide a convenient means of using the aspect ratio estimates. As shown in Appendix B, for an aspect ratio of 1.0, the difference in ice mass between the spherical and hexagonal column assumption is $4 \%$.

Hexagonal column geometry overestimates the mass for particles with size range of $100-200 \mu \mathrm{m}$. This is not surprising, since this is the size range where ice crystals begin to develop branches or extensions, becoming more complex and less compact (Bailey and Hallett, 2004, 2009). In other words, ice particles in this size range have lower density than particles with $D<100 \mu \mathrm{m}$. Since the BL2006 $m$ - $A$ expression and the hexagonal column approximation for ice particle mass are not valid for $100 \mu \mathrm{m}<D<200 \mu \mathrm{m}$, we used the estimated CPI mass for sizes less than $100 \mu \mathrm{m}$, and we did not use any mass estimation for size range of 100-200 $\mu \mathrm{m}$. The exception is for $-65^{\circ} \mathrm{C}<T \leq-55^{\circ} \mathrm{C}$, where we used the BL2006 $m$ - $A$ method to estimate mass from CPI projected area for $D$ between 100 and $200 \mu \mathrm{m}$, because the number of size bins available for $D>200 \mu \mathrm{m}$ is limited (See Fig. 4, 
where it shows that data for this coldest temperature interval are available only for $D<600 \mu \mathrm{m})$. This appears to be the most accurate approach for this size interval for $T \leq-55^{\circ} \mathrm{C}$, which is critical for determining $m-D$ expressions for these colder temperature intervals. The variables in the smallest bin size $(10-20 \mu \mathrm{m})$ are not included in our analysis due to large values of area and mass ratios for this bin size, indicating ice spheres. Although small particles can be spherical, there is an abrupt change in both the area and mass ratio from first size bin to the second size bin; however, for other bin transitions, there is no abrupt change. This might be a size-resolution limitation of the optics that tends to make the images for the smallest size bin appear quasi-spherical.

McFarquhar et al. (2013) discussed that a widely accepted lower limit is not available for the CPI, and they found that it was difficult to extract useful shape information from CPI images for particles with $D<35 \mu \mathrm{m}$ for mixed-phase arctic clouds. However, in our study, shape is not a concern for the CPI size range we are using $(20 \mu \mathrm{m}<D<100 \mu \mathrm{m})$ since we assume hexagonal column geometry and only require length and width measurements, which are estimated for these sizes from a data processing algorithm developed at SPEC Inc.

\section{Mass and area relationships}

Figure S5 shows $m-D$ and $A-D$ expressions and data points for all PSDs for all temperatures considered here. Also shown in this figure are the mean and standard deviation in each size bin. In this way, the natural variability of the $m-D$ and $A-D$ PSD data is presented. While in principle each PSD can be used to produce an $m-D$ or $A-D$ expression, in practice only the mean PSDs in $5^{\circ} \mathrm{C}$ temperature intervals were used to develop the $m-D$ and $A-D$ expressions (explained in Sect. 2.3 and in the Supplement, Fig. S6). Although the averaging process reduces scatter, the coherency of the curves in Fig. S6 is somewhat surprising. The natural variability associated with ice particle mass measurements was minimized in two ways, thus facilitating the curve-fitting process. First, $m$ was estimated from the BL2006 $m$ - $A$ relationship for $D>200 \mu \mathrm{m}$ (which represents the mean $m$ - $A$ behavior in a self-consistent way and thus removes much of the natural variability in $m$ ), and, second, variability was reduced by averaging the SPARTICUS PSD within each $5{ }^{\circ} \mathrm{C} T$ interval, as described in Sect. 2, producing one mean PSD of number, area, and mass concentration for each $T$ interval. The latter can be seen in Figs. S5 and S6. The coherency of these data makes it amenable to curve fitting with high precision. McFarquhar et al. (2007) showed that there is considerable variability in the $m-D$ expression during aircraft measurements of stratiform regions of mesoscale convective systems, and they used a different $m-D$ expression for each flight. The variability in our study differs for the reasons stated above. Moreover, as we show further in this section, the variability in $m-D$ relationship based on 13 flights in syn- optic cirrus clouds during SPARTICUS does not exceed $32 \%$ of the mean bin mass value, having a mean overall value of $13.48 \%$.

If ice particle morphology does not vary much within the ice clouds sampled, then our $m-D$ expressions should be representative of all ice particles for a given cloud type (continental midlatitude synoptic or anvil cirrus clouds) and temperature interval. Ice particle images from various types of cirrus clouds tend to support this assumption, indicating high-density, blocky-shaped irregular crystals with some bullet rosettes and side planes at larger sizes (e.g., Lawson et al., 2006b; Baker and Lawson, 2006b). However, if there is a radical departure from this morphology genre and planar ice crystals having low aspect ratios (i.e., $c$ axis to $a$ axis ratio where $c$ axis is length of the prism face) dominate, our $m-D$ expressions could overestimate ice particle mass by a factor of $\sim 3$ (Lawson, 2016). Such reasoning may explain findings from Arctic mixed-phase clouds, where Jackson et al. (2012) showed that the application of habit-specific $m$ $D$ relationships applied to size/shape distributions in arctic stratocumulus clouds during Indirect and Semi-Direct Aerosol Campaign (ISDAC) over the North Slope of Alaska had better agreement with the measured IWC (mean difference is $\sim 50 \%$ ) than did the application of the BL2006 approach to the measured size distributions (mean difference is $\sim 100 \%$ ). Similar findings from Arctic mixed-phase clouds are reported in Avramov et al. (2011).

A curve fit based on SPARTICUS synoptic mean PSDs for $-40^{\circ} \mathrm{C} T \leq-20^{\circ} \mathrm{C}$ is shown in Fig. 3 by the blue curve. This result differs markedly from previous studies where the relationship between $\log (m)$ and $\log (D)$ is linear, rather than a slowly varying curve as shown here. This finding is due to extending the range of ice particle size to smaller sizes, which was made possible by using data from the CPI probe. The $m-D$ line corresponding to ice spheres is shown for reference since for a given $D$, the ice particle mass cannot exceed this value. Also shown is the curve fit for ice particle mass based on SCPP and CPI $m-D$ measurements and estimates, respectively (the black curve). These SCPP data are described in detail in Sect. 4.1, but here it is sufficient to say that the $827 m$ - $D$ measurements (with ice particle shapes corresponding to this temperature range) were grouped into size intervals and the mean values within each size interval are plotted in Fig. 3 (purple filled circles). The close agreement between the blue and black curves indicates that ice particle masses derived from 2D-S data are adequate surrogates for the SCPP $m-D$ measurements. This agreement, mentioned in Sect. 2.1, forms part of the rationale for this study as described in that section.

Values of mean dimension, mass, and projected area were first calculated for each $5^{\circ} \mathrm{C} T$ interval, and plots of $m-D$ and $A-D$ expressions were provided for each $5{ }^{\circ} \mathrm{C} T$ interval (Fig. S6). It was then observed that $m-D$ and $A-D$ expressions for $5^{\circ} \mathrm{C} T$ intervals have negligible differences within the larger temperature ranges of $-40^{\circ} \mathrm{C}<T<-20^{\circ} \mathrm{C}$, 
Table 1. Polynomial curve fits of the form $\ln m=a_{0}+a_{1} \ln D+a_{2}(\ln D)^{2}$ for synoptic and anvil cirrus clouds sampled during SPARTICUS, where $m$ is in grams and $D$ is in cm. The only exception is for synoptic cirrus between -20 and $-40^{\circ} \mathrm{C}$, where SCPP data were used in lieu of SPARTICUS data, as shown in Fig. 3. The number of $m-D$ samples is given by $N$, along with the coefficient of determination $\left(R^{2}\right)$ of the curve fit. See Sect. 3 for details.

\begin{tabular}{lrrrrr}
\hline Temperature range & $a_{0}$ & $a_{1}$ & $a_{2}$ & $N$ & $R^{2}$ \\
\hline Synoptic cirrus clouds & & & & & \\
\hline$-40^{\circ} \mathrm{C}<T \leq-20^{\circ} \mathrm{C}$ & -6.72924 & 1.17421 & -0.15980 & 201 & 0.99702 \\
$-55^{\circ} \mathrm{C}<T \leq-40^{\circ} \mathrm{C}$ & -7.21010 & 1.26123 & -0.12184 & 139 & 0.99507 \\
$-65^{\circ} \mathrm{C}<T \leq-55^{\circ} \mathrm{C}$ & -11.34570 & -0.45436 & -0.29627 & 54 & 0.99283 \\
\hline Anvil cirrus clouds & & & & & \\
\hline$-40^{\circ} \mathrm{C}<T \leq-20^{\circ} \mathrm{C}$ & -6.67252 & 1.36857 & -0.12293 & 226 & 0.99773 \\
$-55^{\circ} \mathrm{C}<T \leq-40^{\circ} \mathrm{C}$ & -6.44787 & 1.64429 & -0.07788 & 160 & 0.98368 \\
$-65^{\circ} \mathrm{C}<T \leq-55^{\circ} \mathrm{C}$ & -9.24318 & 0.57189 & -0.17865 & 49 & 0.98285 \\
\hline
\end{tabular}

Table 2. Polynomial curve fits of the form $\ln A=a_{0}+a_{1} \ln D+a_{2}(\ln D)^{2}$ for synoptic and anvil cirrus clouds sampled during SPARTICUS, where $A$ is in $\mathrm{cm}^{2}$ and $D$ is in $\mathrm{cm}$. The number of $A-D$ samples is given by $N$, along with the coefficient of determination $\left(R^{2}\right)$ of the curve fit.

\begin{tabular}{lrrrrr}
\hline Temperature range & $a_{0}$ & $a_{1}$ & $a_{2}$ & $N$ & $R^{2}$ \\
\hline Synoptic cirrus clouds & & & & & \\
\hline$-40^{\circ} \mathrm{C}<T \leq-20^{\circ} \mathrm{C}$ & -2.46356 & 1.25892 & -0.07845 & 201 & 0.99803 \\
$-55^{\circ} \mathrm{C}<T \leq-40^{\circ} \mathrm{C}$ & -2.60478 & 1.32260 & -0.05957 & 139 & 0.99781 \\
$-65^{\circ} \mathrm{C}<T \leq-55^{\circ} \mathrm{C}$ & -4.63488 & 0.54233 & -0.13260 & 54 & 0.99784 \\
\hline Anvil cirrus clouds & & & & & \\
\hline$-40^{\circ} \mathrm{C}<T \leq-20^{\circ} \mathrm{C}$ & -2.40314 & 1.29749 & -0.07233 & 226 & 0.99852 \\
$-55^{\circ} \mathrm{C}<T \leq-40^{\circ} \mathrm{C}$ & -2.38913 & 1.40166 & -0.05219 & 160 & 0.99753 \\
$-65^{\circ} \mathrm{C}<T \leq-55^{\circ} \mathrm{C}$ & -2.43451 & 1.60639 & -0.01164 & 49 & 0.98606 \\
\hline
\end{tabular}

$-55^{\circ} \mathrm{C}<T<-40^{\circ} \mathrm{C}$, and $-65^{\circ} \mathrm{C}<T<-55^{\circ} \mathrm{C}$. In order to keep $m-D$ and $A-D$ expressions as simple as possible without losing accuracy, the coefficients of polynomial fits are not provided for each $5^{\circ} \mathrm{C} T$ interval. Instead, mean PSDs were determined for each of the above mentioned three temperature categories and second-order polynomial curve fits were calculated for each category as shown in Tables 1 and 2. The "goodness of fit" is given by the $R^{2}$ in these tables, and the number of mean data points used is also indicated.

Greater accuracy is obtained by using the fit equation for a specific temperature interval rather than using the fit equation corresponding to all temperatures sampled. While the temperature-dependent $A-D$ and $m-D$ fits are similar, and the $R^{2}$ values for the temperature-independent $A-D$ and $m-D$ fits in Fig. S5 (0.9924 and 0.9954, respectively, based on all temperatures) are similar to those in Tables 1 and 2, the actual values predicted by these temperature-dependent fits does render more accurate $A$ and $m$ estimates, as shown in Figs. 4 and S6. Since the fits are similar, a climate model can use these fits without using any smoothing function when crossing temperature boundaries. In fact, this $m-D / A-D$ scheme has been used in a global climate model (GCM), as described in Eidhammer et al. (2016).

Fontaine et al. (2014) found that it is not proper to employ a single temperature-independent $m-D$ expression for all clouds, because such expression neglects the considerable natural variability of mass as a function of dimension. We show that it is sufficient to categorize $m-D$ and $A-D$ expressions into three temperature ranges for a given cloud. Within each of these temperature ranges, negligible differences are observed between $m-D$ and $A-D$ expressions corresponding to $5^{\circ} \mathrm{C} T$ intervals. The resulting temperature-dependent curve fits are depicted in Fig. 4, where it is shown that for $T<-55^{\circ} \mathrm{C}$, the $m-D$ curves are considerably different for both synoptic and anvil cirrus relative to the warmer temperature intervals.

It is also seen from Fig. 4 that the mean dependence of ice particle mass on particle size is not predicted to vary substantially between ice clouds of different type (i.e., synoptic vs. anvil) for a given temperature regime. The latter differs from the results of $\mathrm{H} 2010$, where they showed that $m-D$ power laws for anvil ice clouds yield masses about a factor of 2 


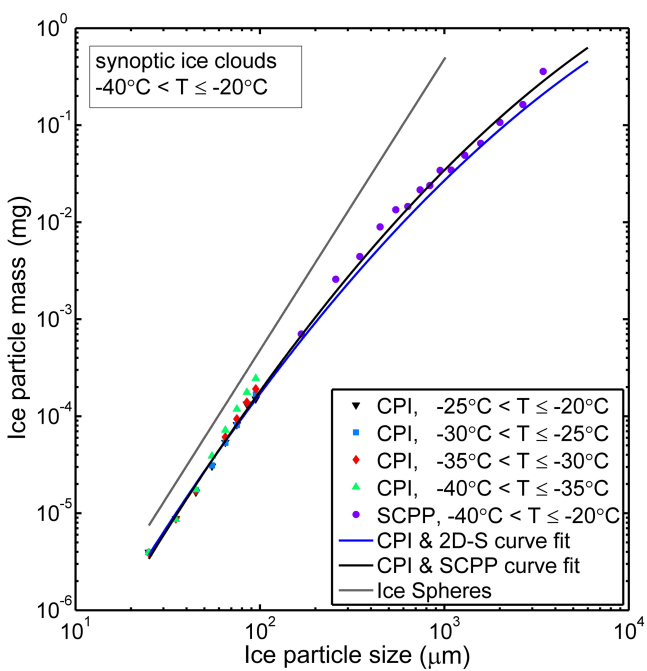

Figure 3. Dependence of ice particle mass on $D$ for mean PSDs sampled from synoptic cirrus clouds during SPARTICUS for $-40^{\circ} \mathrm{C}<T=-20{ }^{\circ} \mathrm{C}$ (blue curve fit based on CPI and 2D-S data), where a single mean PSD is the mean of all PSD contained within a $5{ }^{\circ} \mathrm{C}$ temperature interval. Also shown are CPI and SCPP data that are grouped into size bins for the indicated temperature ranges and the black curve fit based on these data (see Table 1 for equation). The gray line for ice spheres gives the maximum possible mass for a given $D$.

larger than for synoptic ice clouds. It is possible that the similarity in $m-D$ expressions found here regarding synoptic and anvil ice clouds is an artifact if ice particle masses for a given $A$ are quite different between these cloud types.

The second-order polynomial $A-D$ curve fits were provided in a similar way that $m-D$ curve fits were obtained, and they are shown in Table 2. An example of the mean PSD data and the polynomial $A-D$ curve fit is shown in Fig. 5 for $-40^{\circ} \mathrm{C}<T \leq-20^{\circ} \mathrm{C}$. Again the PSD averaging process greatly reduces the spread in area for a given size. More scatter is seen at the largest sizes since the size bins here are populated by relatively few ice particles. The line for ice spheres indicates the maximum possible projected area for a given $D$. For each temperature interval, fractional uncertainties for each 2D-S size bin were calculated as shown in Fig. 6 only for the temperature intervals having three or more PSDs. Fractional uncertainties are expressed as the $\sigma$ of projected area divided by the mean projected area for each size bin midpoint. Uncertainties are highly variable and range between 0 and $28 \%$ of the mean bin $A$ value, having a mean overall value of $11.0 \%$. Uncertainties tend to be 0 for $D=10 \mu \mathrm{m}$ since particles in this size bin $(5-15 \mu \mathrm{m})$ generally shadow only one pixel in both vertical and time (horizontal) dimensions. Similar to Fig. 6, we calculated the fractional uncertainties for the mean ice particle mass in each size bin of the measured PSDs (figure not shown). The pattern for the mass fractional uncertainties is similar to that for area fractional uncertainties. Mass uncertainties range between 0 and

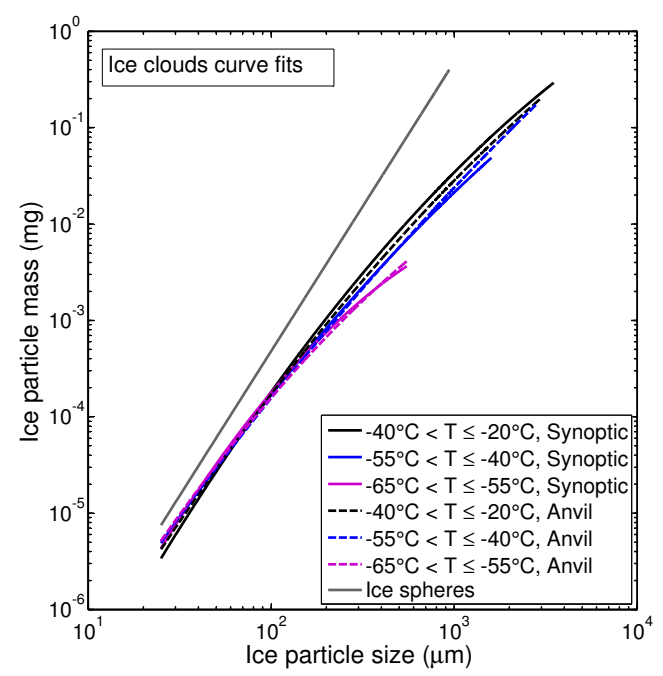

Figure 4. Comparison of all the curve fits in Table 1 for each temperature regime (indicated by color) and cloud type (indicated by line type; solid or dashed). The anvil and synoptic curve fits are very similar.

$32 \%$ of the mean bin mass, with a mean overall fractional uncertainty of $13.48 \%$.

It is important to know whether the measured ice particle area and masses are internally consistent here since ice cloud properties like $D_{\mathrm{e}}$ and the mass-weighted fall speed $\left(V_{\mathrm{m}}\right)$ depend on the ice particle $m / A$ ratio. The maximum value of the $m$ / $A$ ratio is given by an ice sphere. Thus a test for internal consistency is to calculate relative $m / A$, which is defined as

$R=\frac{\left(\frac{m}{A}\right)_{\text {particle }}}{\left(\frac{m}{A}\right)_{\text {sphere }}}$.

See Appendix $\mathrm{C}$ for the definition of all symbols. This ratio should not exceed a value of 1.0. The data used to produce Tables 1 and 2 were tested in this way and this ratio never exceeded a value of 1.0. However, when curve fits provided only by $2 \mathrm{D}-\mathrm{S}$ probe are used, this ratio exceeded the value of 1.0 for size less than $20 \mu \mathrm{m}$ where $A$ measurements are poorest. An example is shown in Fig. 7 for $-40{ }^{\circ} \mathrm{C}<T \leq$ $-20^{\circ} \mathrm{C}$. As shown by Heymsfield et al. (2002) and others, this ratio should increase with decreasing ice particle size, which is also demonstrated here.

\section{Comparison of curve fits with SCPP measurements of single ice particle mass}

\subsection{SCPP measurements of ice particle masses characteristic of cold ice clouds}

The $m-D$ expressions in Table 1, based on CPI and 2D-S measurements, are valid to the extent that the BL2006 m-A 


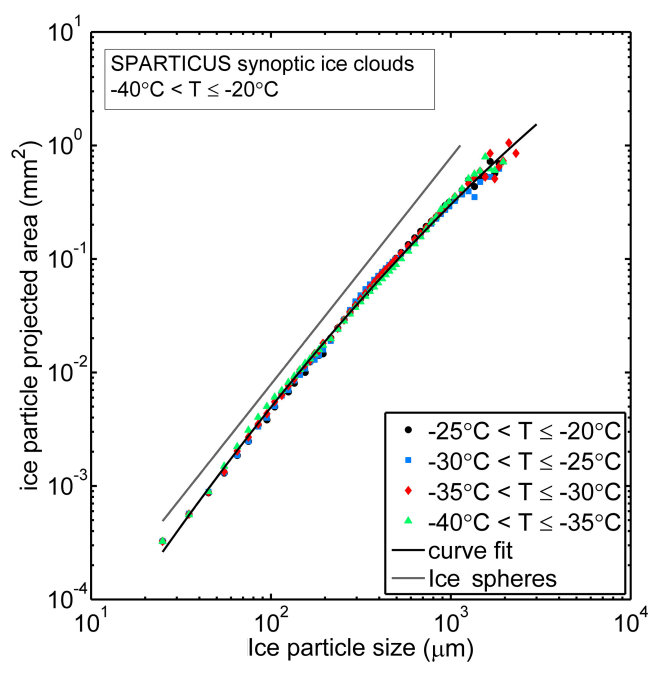

Figure 5. Dependence of ice particle projected area $(A)$ on $D$ based on mean PSD within the indicated temperature regime. The CPI and 2D-S data have been grouped into size bins, and the black solid curve is a fit to these data sets (see Table 2 for equation).

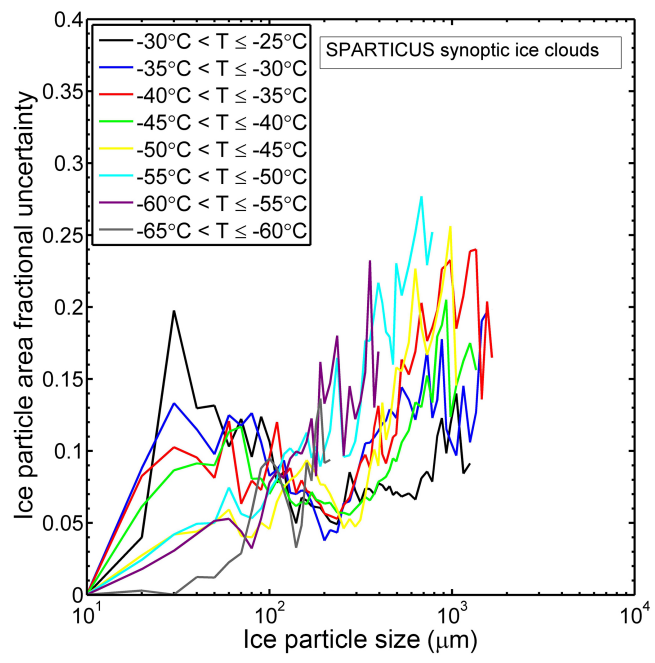

Figure 6. Fractional uncertainties (standard deviation/mean) for the mean ice particle projected area in each bin of the measured PSDs. Only temperature intervals having more than two PSDs are considered.

relationship is valid at those temperatures and sizes. Testing of the $m-D$ expression for $-40^{\circ} \mathrm{C}<T \leq-20^{\circ} \mathrm{C}$ by using ice particle masses from habits formed in this same temperature range is pursued in this section.

The $m-D$ relationships developed in the last section are void of uncertainty estimates, which are needed in remote sensing for estimating the uncertainties of retrieved cloud properties. To estimate the uncertainty $(\sigma)$ associated with the curve fits in Table 1, the field measurements described in M1990 are used.

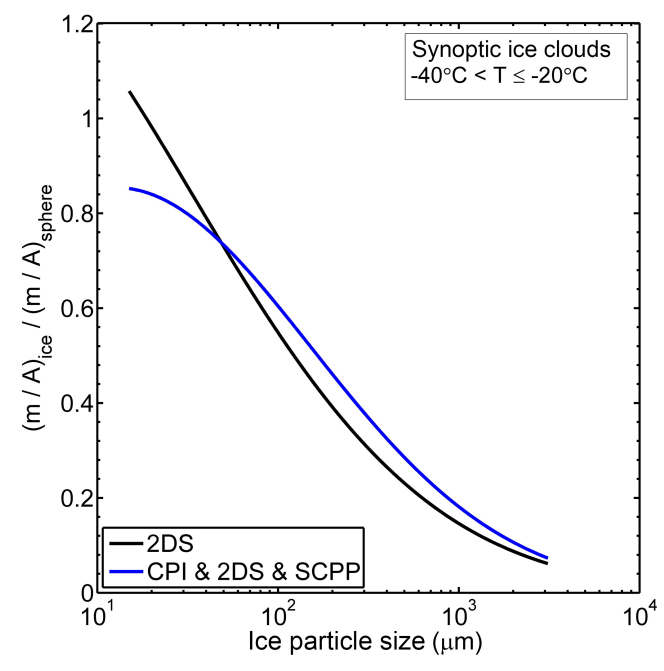

Figure 7. The $m$ / $A$ ratio for ice particles normalized by the corresponding $m / A$ ratio for ice spheres using the $m-D$ and $A-D$ curve fits appropriate for the indicated temperature regime. The blue curve is based on Tables 1 and 2, but the black curve is only based on 2D-S data.

The distribution of ice particle masses with respect to size is shown in Fig. 8 for the cold-temperature habits in the SCPP measurements. The laboratory experiments of Bailey and Hallett $(2004,2009)$ found that at significant or substantial supersaturations with respect to ice, bullet rosettes dominate between -70 and $-40^{\circ} \mathrm{C}$ while complex plate-like crystals (e.g., side planes) dominate between -40 and $-20^{\circ} \mathrm{C}$. At very low supersaturations near ice saturation, hexagonal columns with aspect ratios near unity were common for $-70^{\circ} \mathrm{C}<T<-20^{\circ} \mathrm{C}$. The results in Fig. 8 are generally consistent with the laboratory results, with side planes dominating over bullet rosettes, although short columns were most abundant which suggests low supersaturations were common in these clouds for $T<-20^{\circ} \mathrm{C}$. Indeed, low supersaturations appear to be common in clouds where $T<-20^{\circ} \mathrm{C}(\mathrm{C} 2013)$. While hexagonal columns are generally not the dominant ice particle shape for $T<-20^{\circ} \mathrm{C}$, compact irregular ice particles are very common and often dominate $N$ at smaller sizes (Korolev and Isaac, 2003; Lawson et al., 2006a; Baker and Lawson, 2006b, C2013). The similarity between the hexagonal column $m-D$ expression and the $\mathrm{C} 2013 m-D$ expression in Fig. 1 suggests short hexagonal columns may serve as a proxy for compact irregular ice. Ice particles classified as unrimed having these shapes were used in Fig. 8, although some light riming is possible. The three main categories of ice particle shape are color-coded in Fig. 8, with columnar ice particles more common at small-to-intermediate sizes, side plane type ice particles more common at intermediateto-large sizes, and bullet rosettes more common at intermediate sizes. The $m-D$ curve fit, based on CPI and SCPP measurements, is from Table 1 for synoptic ice clouds for $-40^{\circ} \mathrm{C}<T \leq-20^{\circ} \mathrm{C}$. 


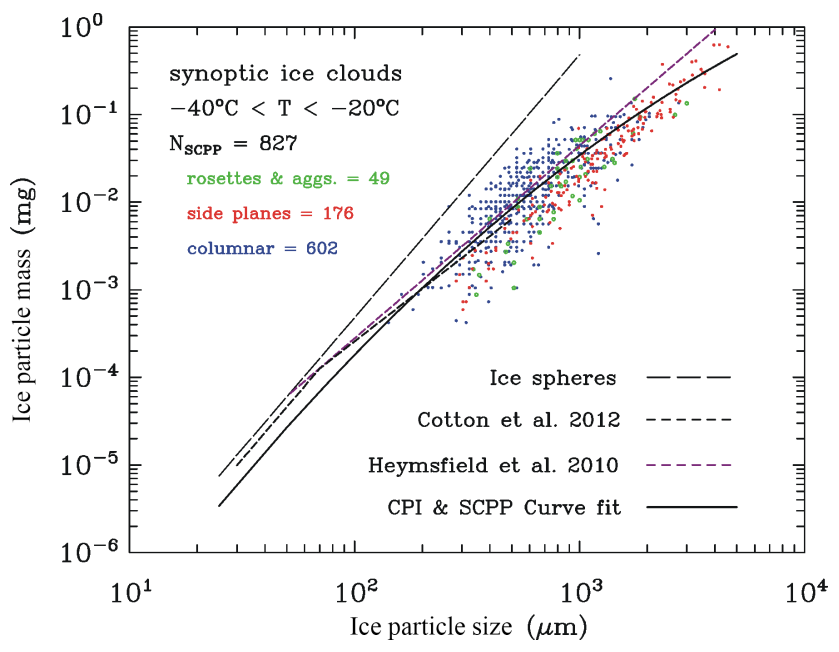

Figure 8. The $m-D$ curve fit based on SCPP and CPI data (for indicated temperature regime) is compared with individual ice particle $m-D$ measurements from SCPP, corresponding to ice particle shapes originating from similar temperatures. The number of ice particles sampled in each shape category is indicated. Also shown are comparisons with two other studies that derived $m-D$ power laws from ice cloud field data.

Also shown are the recently published $m-D$ power law relationships of $\mathrm{C} 2013$ and $\mathrm{H} 2010$ that were obtained from synoptic $\left(-60^{\circ} \mathrm{C}<T<-20^{\circ} \mathrm{C}\right)$ and from both synoptic and anvil $\left(-60^{\circ} \mathrm{C}<T<0^{\circ} \mathrm{C}\right)$ ice clouds, respectively. These relationships are plotted over the size range used to produce them. The $\mathrm{C} 2013$ relationship consists of two lines and follows the curve fit remarkably well for $D>100 \mu \mathrm{m}$, with differences never exceeding $50 \%$. The $\mathrm{H} 2010$ relationship consists of a single line and also approximates the curve fit well, except for $D<100 \mu \mathrm{m}$ and $D>1000 \mu \mathrm{m}$ where differences can reach about $100 \%$.

Figure 9 shows a polynomial curve fit based on mass estimates from the 2D-S (M7 processing) and CPI probes for sizes greater than $200 \mu \mathrm{m}$ and less than $100 \mu \mathrm{m}$, respectively. Also shown are SCPP data in which the ice particle measurements were binned into size intervals of $100 \mu \mathrm{m}$ between 100 and $1000 \mu \mathrm{m}$, with subsequent intervals of 200,200 , $400,600,600$, and $1000 \mu \mathrm{m}$ (up to $4 \mathrm{~mm}$ ) at larger sizes to provide adequate sampling statistics. The $\sigma$ within each size interval was calculated for $m$ and $D$ as shown by the vertical and horizontal red bars, respectively. The intersection point marks the mean value for $m$ and $D$ in each interval. The $m-D$ curve fit for SPARTICUS synoptic ice clouds for $-40^{\circ} \mathrm{C}<T \leq-20^{\circ} \mathrm{C}$ is extrapolated to $4 \mathrm{~mm}$ in Fig. 9 for comparison with the masses and sizes of these 827 ice particles sampled during SCPP. In this way, the SPARTICUS measurements roughly coincide with the temperatures of origin of these SCPP cold-habit ice particles. Although the BL2006 $m-A$ expression was derived from a subset ( 865 ice particles) of the 3-year SCPP field study (4869 ice parti-

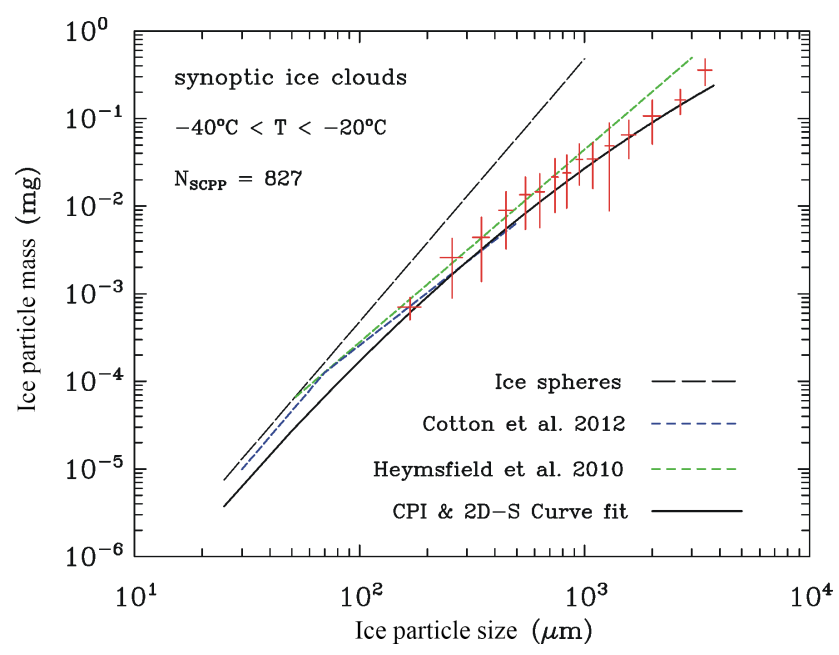

Figure 9. Same as Fig. 8, except the $m-D$ curve fit is based on SPARTICUS (2D-S and CPI) data and the SCPP field data have been grouped into size bins; shown are the standard deviations $(\sigma)$ in $m$ and $D$ for each size bin. Mean values for $m$ and $\mathrm{D}$ are shown by the intersection of the $\sigma$-bars.

cles), a detailed comparison of the subset of 827 cold-habit ice particles used here and the BL2006 subset revealed that only $17.5 \%$ of the ice particles were common to both subsets. Thus, a comparison of an $m-D$ expression based on SPARTICUS data (derived from the BL2006 $m$ - $A$ expression) with the cold-habit $m-D$ measurements from SCPP is still a meaningful comparison. It is seen in Fig. 9 that the SPARTICUS curve fit is well within the $\sigma$ values of SCPP mass for all size intervals and is often close to the mean $m$ values, except for the largest size bin having a relatively small sample size. The same is true for the C2013 m-D expression when it is extended to larger ice particle sizes.

Getting still more quantitative, the percent difference of the SCPP cold-habit mean mass for a given size interval was compared with the corresponding ice particle mass from the SPARTICUS curve fit. In other words, the percent difference is calculated as $100 \times\left(m_{\text {SCPP }}-m_{\text {SPARTICUS }}\right) /\left[\left(m_{\text {SCPP }}+m_{\text {SPARTICUS }}\right) / 2\right]$ for each size bin (figure not shown). Percent differences are less than $53 \%$ in all size bins, and the mean percent difference for all size bins was $28 \%$. Note that percent difference is calculated on the normal scale and not on the logarithmic scale. Given the natural variability observed for ice particle masses, this level of agreement is considered good. Moreover, the $m-D$ expressions from two completely independent studies, C2013 and H2010, conform closely to the SPARTICUS curve fit and the mean cold-habit (i.e., SCPP) $m$ values. The convergence in agreement of the SPARTICUS curve fit with the cold-habit SCPP $m-D$ measurements, the C2013 study and the H2010 study suggest that the SPARTICUS $m-D$ curve fit is a reasonable representation of ice particle mass over the particle size range considered here. It uses the 


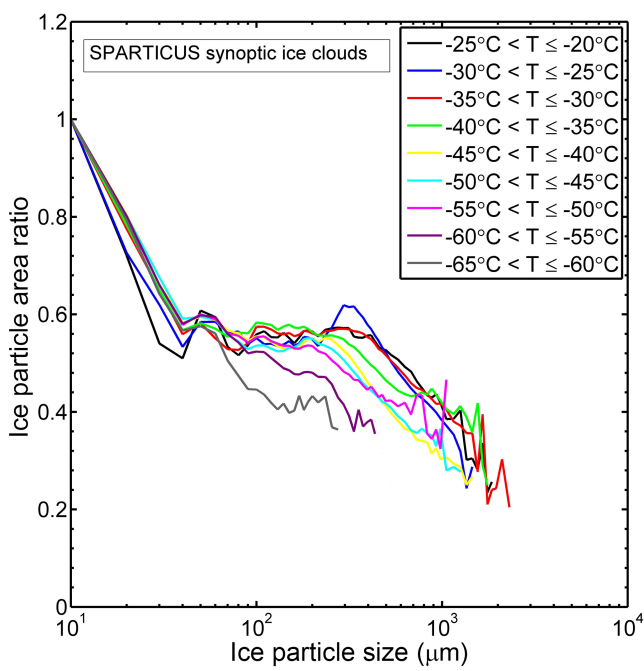

Figure 10. Mean area ratios for each mean PSD size bin are shown as a proxy for ice particle shape. Temperature intervals corresponding to each mean PSD are indicated for synoptic ice clouds.

BL2006 $m$ - $A$ relationship to estimate $m$ for $D \geq 200 \mu \mathrm{m}$ and our CPI $m-A$ method for $D \leq 100 \mu \mathrm{m}$, and its agreement with the SCPP cold-habit $m-D$ measurements validates its use up to $4 \mathrm{~mm}$ for $-40^{\circ} \mathrm{C}<T \leq-20^{\circ} \mathrm{C}$.

\subsection{Extension to colder temperatures}

As postulated in Sect. 2, given a validated $m-D$ expression from SPARTICUS and SCPP data between -40 and $-20^{\circ} \mathrm{C}$, this methodology of obtaining $m-D$ expressions from SPARTICUS data should be appropriate at colder temperatures if ice particle shape does not significantly change. Here we use the ice particle $A_{\mathrm{r}}$ as a proxy for ice particle shape. The mean ice particle $A_{\mathrm{r}}$ for each size bin is shown for each $5^{\circ} \mathrm{C}$ temperature interval in Figs. 10 and 11 for synoptic and anvil cirrus, respectively. Values of $A_{\mathrm{r}}$ are similar among all temperature intervals excepting those for $T \leq-55^{\circ} \mathrm{C}$. For $D>60 \mu \mathrm{m}$, these two coldest intervals exhibit $A_{\mathrm{r}}$ less than that for $T>-55^{\circ} \mathrm{C}$ in both synoptic and anvil ice clouds.

For purposes of calculating PSD $A, m$, and radar reflectivity $(Z)$, the $A_{\mathrm{r}}$ changes at these larger sizes are considered more critical than the $A_{\mathrm{r}}$ changes at smaller sizes. It is therefore argued that for these applications, the noted methodology of obtaining $m-D$ and $A-D$ expressions from SPARTICUS data should be appropriate at colder temperatures down to $-55^{\circ} \mathrm{C}$. For $T \leq-55^{\circ} \mathrm{C}$, it appears that ice particle shape changes, and it is possible that the ice particle geometry changes in such a way that the BL2006 $m$ - $A$ expression is no longer valid. For example, if the BL2006 $m$ - $A$ expression implicitly assumes relatively compact ice particles growing in three dimensions, and the ice particle shape changes to planar crystals with 2-D growth dominating, then the BL2006 $m$ - $A$ expression may perform poorly. We report

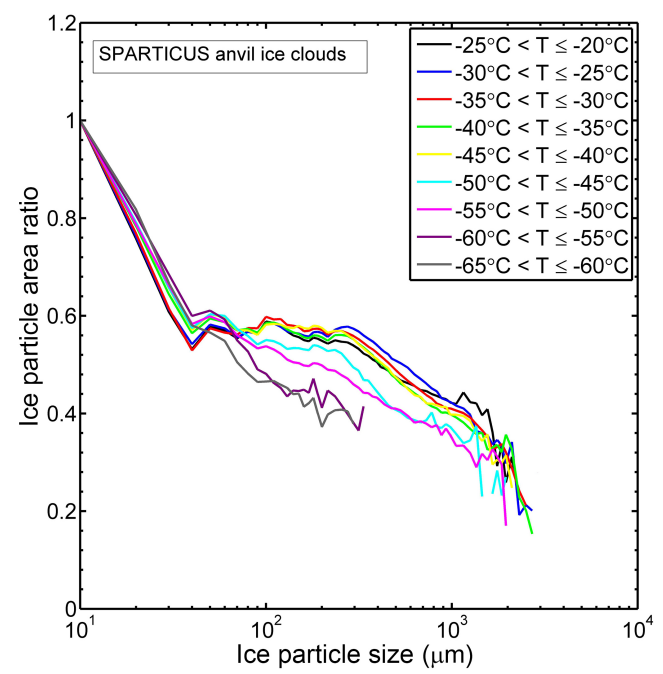

Figure 11. Same as Fig. 10 but for anvil ice clouds.

$m-D$ results for these coldest temperatures (Table 1), but with the caveat that these $m-D$ expressions are highly uncertain. Additional research is needed to test these results. Moreover, this study addresses only midlatitude synoptic and anvil ice clouds over land, and results may have been different if marine anvil cirrus, orographic cirrus, and/or Arctic ice clouds were considered.

\section{Uncertainties in $m-D$ and $A-D$ expressions}

Conventional $m-D$ and $A-D$ expressions use power law relationships of the form

$m=\alpha D^{\beta}$

$A=\gamma D^{\delta}$

to estimate ice particle mass and projected area, where $\alpha, \beta$, $\gamma$, and $\delta$ are constants. This study indicates that these terms should not be constants over all ice particle sizes, but that they can be approximated as constants over a range of particle size with good accuracy. The second-order polynomials used in this study have the form

$\ln x=a_{o}+a_{1} \ln D+a_{2}(\ln D)^{2}$,

where $x$ is either $m$ or $A$, and $a_{o}, a_{1}$, and $a_{2}$ are constants. Differentiating Eq. (4) with respect to $\ln (D)$ gives the slope of this curve, which is $\beta$ for the mass case:

$\frac{\partial(\ln m)}{\partial(\ln D)}=\beta=a_{1}+2 a_{2} \ln D$.

Thus, $\beta$ is a function of $D$ and, for a given $D, \alpha$ can be solved for by equating the $m-D$ power law (Eq. 2) with polynomial fit (Eq. 4)

$\alpha=\frac{\exp \left[a_{o}+a_{1} \ln D+a_{2}(\ln D)^{2}\right]}{D^{\beta}}$. 
Table 3. Uncertainty estimates for mass-dimension power $\beta$ for synoptic cirrus clouds.

\begin{tabular}{|c|c|c|c|c|c|}
\hline \multirow[t]{3}{*}{ Temperature range } & \multicolumn{5}{|c|}{ Ice particle size $(\mu \mathrm{m})$} \\
\hline & 50 & 150 & 500 & 1500 & 4500 \\
\hline & \multicolumn{5}{|c|}{ Power $\beta$} \\
\hline$-25^{\circ} \mathrm{C}<T \leq-20^{\circ} \mathrm{C}$ & 2.792 & 2.455 & 2.085 & 1.748 & 1.411 \\
\hline$-30^{\circ} \mathrm{C}<T \leq-25^{\circ} \mathrm{C}$ & 2.846 & 2.449 & 2.015 & 1.618 & 1.221 \\
\hline$-35^{\circ} \mathrm{C}<T \leq-30^{\circ} \mathrm{C}$ & 2.773 & 2.429 & 2.053 & 1.710 & 1.367 \\
\hline$-40^{\circ} \mathrm{C}<T<-35^{\circ} \mathrm{C}$ & 2.642 & 2.371 & 2.073 & 1.802 & 1.530 \\
\hline$-45^{\circ} \mathrm{C}<T \leq-40^{\circ} \mathrm{C}$ & 2.556 & 2.254 & 1.923 & 1.621 & 1.320 \\
\hline$-50^{\circ} \mathrm{C}<T \leq-45^{\circ} \mathrm{C}$ & 2.549 & 2.276 & 1.977 & 1.704 & 1.431 \\
\hline$-55^{\circ} \mathrm{C}<T \leq-50^{\circ} \mathrm{C}$ & 2.495 & 2.322 & 2.133 & 1.960 & 1.787 \\
\hline$-60^{\circ} \mathrm{C}<T \leq-55^{\circ} \mathrm{C}$ & 2.686 & 2.064 & 1.382 & - & 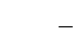 \\
\hline$-65^{\circ} \mathrm{C}<T \leq-60^{\circ} \mathrm{C}$ & 2.863 & 1.732 & - & - & - \\
\hline Mean $\beta$ & 2.689 & 2.261 & 1.955 & 1.738 & 1.438 \\
\hline Standard deviation of $\beta$ & 0.129 & 0.220 & 0.225 & 0.109 & 0.168 \\
\hline Mean uncertainty (\%) & 9.031 & & & & \\
\hline
\end{tabular}

The same approach is used to solve for $\delta$ and $\gamma$ for a given $D$. Uncertainties for the $m-D$ and $A-D$ polynomial fit expressions can be characterized by estimating $\sigma$ for $\alpha$ and $\gamma$ using field observations of $m$ and $A$ and estimating $\sigma$ for $\beta$ and $\delta$ using selected values of $D$ in the fit equations. This is possible due to the relatively low uncertainty in $\beta$ and $\delta$, as described below.

\subsection{Uncertainties in the exponent of power law expressions}

Values of $\beta$ and $\delta$ are evaluated at five ice particle sizes and for all temperature intervals sampled for synoptic and anvil ice clouds, and are shown in Tables 3-6. For the two coldest temperature intervals, values are not shown for the two largest size categories since PSD did not extend to these sizes at these temperatures. The mean and $\sigma$ for $\beta$ are calculated for each of the five ice particle sizes selected. Then, the mean uncertainty is expressed as a percent for the fraction mean $\sigma /$ mean $\beta$ that is averaged over all five selected sizes. This mean fractional uncertainty is the final uncertainty estimate for $\beta$ and $\delta$ that can be applied for any size and temperature range. A key finding is that mean uncertainties for $\beta$ do not exceed $9.1 \%$ and mean uncertainties for $\delta$ do not exceed $8.5 \%$. This indicates that most of the scatter in measurements of ice particle mass and area can be attributed to uncertainties in $\alpha$ and $\gamma$, respectively.

Another interesting feature of Tables 3-6 is the evolution of $\beta$ and $\delta$ with size. At the smallest sizes, ice particles tend to be quasi-spherical or isometric (Korolev and Isaac, 2003), with $\beta$ and $\delta$ approaching values of 3 and 2, respectively, with decreasing size. As ice particles grow in size, they become more complex, often displaying branches in three dimensions (e.g., bullet rosettes and side planes). This produces less mass per unit length, and $\beta$ and $\delta$ decrease. In
Table 4. Same as Table 3 but for anvil cirrus clouds.

\begin{tabular}{|c|c|c|c|c|c|}
\hline \multirow[t]{3}{*}{ Temperature range } & \multicolumn{5}{|c|}{ Ice particle size $(\mu \mathrm{m})$} \\
\hline & 50 & 150 & 500 & 1500 & 4500 \\
\hline & \multicolumn{5}{|c|}{ Power $\beta$} \\
\hline$-25^{\circ} \mathrm{C}<T \leq-20^{\circ} \mathrm{C}$ & 2.614 & 2.387 & 2.138 & 1.911 & 1.683 \\
\hline$-30^{\circ} \mathrm{C}<T \leq-25^{\circ} \mathrm{C}$ & 2.726 & 2.426 & 2.098 & 1.799 & 1.499 \\
\hline$-35^{\circ} \mathrm{C}<T \leq-30^{\circ} \mathrm{C}$ & 2.653 & 2.394 & 2.110 & 1.850 & 1.591 \\
\hline$-40^{\circ} \mathrm{C}<T \leq-35^{\circ} \mathrm{C}$ & 2.679 & 2.394 & 2.083 & 1.798 & 1.513 \\
\hline$-45^{\circ} \mathrm{C}<T \leq-40^{\circ} \mathrm{C}$ & 2.655 & 2.370 & 2.058 & 1.773 & 1.488 \\
\hline$-50^{\circ} \mathrm{C}<T \leq-45^{\circ} \mathrm{C}$ & 2.531 & 2.302 & 2.051 & 1.822 & 1.593 \\
\hline$-55^{\circ} \mathrm{C}<T \leq-50^{\circ} \mathrm{C}$ & 2.432 & 2.273 & 2.100 & 1.941 & 1.782 \\
\hline$-60^{\circ} \mathrm{C}<T \leq-55^{\circ} \mathrm{C}$ & 2.533 & 2.105 & 1.637 & - & - \\
\hline$-65^{\circ} \mathrm{C}<T \leq-60^{\circ} \mathrm{C}$ & 2.446 & 1.956 & 1.419 & - & - \\
\hline Mean $\beta$ & 2.585 & 2.290 & 1.966 & 1.842 & 1.593 \\
\hline Standard deviation of $\beta$ & 0.105 & 0.159 & 0.255 & 0.063 & 0.108 \\
\hline Mean uncertainty (\%) & 6.715 & & & & \\
\hline
\end{tabular}

Tables 5 and $6, \delta$ is slightly greater than 2.00 (the maximum theoretical value) at the smallest size for some temperature intervals. This is likely due to inaccuracies in CPI projected area measurements at small sizes and an artifact of the curvefitting process.

\subsection{Uncertainties in prefactors of power law expressions}

Figure 9 shows $\sigma$ for $\mathrm{SCPP} m$ for each size interval. Since changes in $\beta$ account for a relatively small portion of this uncertainty, to a first approximation we can attribute all this uncertainty to $\alpha$. The percent uncertainty averaged over all sizes is calculated as the mean value of the fractional uncertainty of each size interval ( $\sigma /$ size bin mean value) and is equal to $\pm 54.4 \%$ for the mass $\sigma$ values in Fig. 9. This is our estimate for the mean fractional $\sigma$ for $\alpha$ for all ice clouds.

A similar analysis is needed for ice particle projected area, and for that we turn to the fractional uncertainty calculations shown in Fig. 6. The mean percent uncertainty for $\gamma$ based on Fig. 6 is $\pm 11.2 \%$.

These mean $\sigma$ values for $\alpha$ and $\gamma$ should be representative $\sigma$ estimates for the $m-D$ and $A-D$ expressions reported in this paper. Moreover, these uncertainties should be useful in characterizing the uncertainties of retrieved ice cloud properties in various retrieval algorithms.

\section{Application to cloud modeling}

\subsection{Methodology}

In regional and global climate models, the microphysical factors most affecting the cloud radiative forcing and feedback from ice clouds are the ice water path (IWP), the $D_{\mathrm{e}}$ and the $V_{\mathrm{m}}$. While ice cloud optical properties are a strong function of $D_{\mathrm{e}}$, the ice cloud lifetime, coverage, and IWP are 
Table 5. Uncertainty estimates for area-dimension power $\delta$ for synoptic cirrus clouds.

\begin{tabular}{lrrrrr}
\hline Temperature range & \multicolumn{5}{c}{ Ice particle size $(\mu \mathrm{m})$} \\
\cline { 2 - 6 } & 50 & 150 & 500 & 1500 & 4500 \\
\cline { 2 - 6 } & \multicolumn{5}{c}{ Power $\delta$} \\
\hline$-25^{\circ} \mathrm{C}<T \leq-20{ }^{\circ} \mathrm{C}$ & 2.133 & 1.938 & 1.725 & 1.531 & 1.337 \\
$-30^{\circ} \mathrm{C}<T \leq-25^{\circ} \mathrm{C}$ & 2.170 & 1.932 & 1.671 & 1.432 & 1.194 \\
$-35^{\circ} \mathrm{C}<T \leq-30{ }^{\circ} \mathrm{C}$ & 2.140 & 1.927 & 1.693 & 1.480 & 1.267 \\
$-40^{\circ} \mathrm{C}<T \leq-35^{\circ} \mathrm{C}$ & 2.027 & 1.882 & 1.722 & 1.576 & 1.431 \\
$-45^{\circ} \mathrm{C}<T \leq-40^{\circ} \mathrm{C}$ & 2.011 & 1.821 & 1.612 & 1.422 & 1.232 \\
$-50^{\circ} \mathrm{C}<T \leq-45^{\circ} \mathrm{C}$ & 1.941 & 1.810 & 1.666 & 1.534 & 1.403 \\
$-55^{\circ} \mathrm{C}<T \leq-50^{\circ} \mathrm{C}$ & 1.861 & 1.842 & 1.821 & 1.801 & 1.782 \\
$-60^{\circ} \mathrm{C}<T \leq-55^{\circ} \mathrm{C}$ & 1.960 & 1.669 & 1.350 & - & - \\
$-65^{\circ} \mathrm{C}<T \leq-60^{\circ} \mathrm{C}$ & 2.018 & 1.509 & - & - & - \\
\hline Mean $\delta$ & 2.029 & 1.814 & 1.658 & 1.540 & 1.378 \\
\hline Standard deviation of $\delta$ & 0.103 & 0.142 & 0.138 & 0.128 & 0.198 \\
\hline Mean uncertainty $(\%)$ & 8.428 & \multicolumn{3}{c}{} \\
\hline
\end{tabular}

strong functions of $V_{\mathrm{m}}$ (Sanderson et al., 2008; Mitchell et al., 2008). Both $D_{\mathrm{e}}$ and $V_{\mathrm{m}}$ primarily depend on the ice particle $m$ / $A$ ratio. In many climate models, the $D_{\mathrm{e}}$ estimated for the prediction of ice optical properties is not the $D_{\mathrm{e}}$ predicted from the cloud microphysics, introducing an inconsistency between the microphysics and radiation modules of the climate model (Baran, 2012). Moreover, $V_{\mathrm{m}}$ and $D_{\mathrm{e}}$ are generally not treated consistently in terms of the $m / A$ ratio in nearly all cloud, weather prediction, and climate models. Rather, $V_{\mathrm{m}}$ is generally predicted from a power law of the form $V=a_{v} D_{o}^{b_{v}}$, where $a_{v}$ and $b_{v}$ are constants and $D_{o}$ is a characteristic dimension of the ice PSD (e.g., Morrison and Gettelman, 2008). This can result in non-physical behavior that substantially affects the cloud radiative forcing.

These model inconsistencies can be easily rectified by recognizing that ice microphysical and optical properties rest on some fundamental assumptions regarding $m$ and $A$; namely the $m-D$ and $A-D$ power laws (Eqs. 2 and 3). By applying these relationships consistently throughout a climate model (e.g., to predict both $D_{\mathrm{e}}$ and $V_{\mathrm{m}}$ ), self-consistency can be achieved.

While these relationships are commonly used in climate models, it is sometimes not recognized that such power laws are only valid over a limited range of $D$ (examples include Fig. 1 and also Table 1 in Mitchell 1996). To address this by using second-order polynomials poses a conundrum since many physical processes are analytically expressed by integrating $m-D$ and $A-D$ power laws over the PSD. Thus, using second-order polynomial fits may pose a quantum leap in model complexity. To avoid this problem, we propose the following treatment of $m-D$ and $A-D$ expressions.

To make this treatment practical for climate modeling, a procedure was developed that assumes advanced approximate knowledge of the PSD dimension of interest $\left(D_{\mathrm{i}}\right)$. For
Table 6. Same as Table 5 but for anvil cirrus clouds.

\begin{tabular}{lrrrrr}
\hline Temperature range & \multicolumn{5}{c}{ Ice particle size $(\mu \mathrm{m})$} \\
\cline { 2 - 6 } & 50 & 150 & 500 & 1500 & 4500 \\
\cline { 2 - 6 } & \multicolumn{5}{c}{ Power $\delta$} \\
\hline$-25^{\circ} \mathrm{C}<T \leq-20^{\circ} \mathrm{C}$ & 2.023 & 1.899 & 1.763 & 1.639 & 1.515 \\
$-30^{\circ} \mathrm{C}<T \leq-25^{\circ} \mathrm{C}$ & 2.108 & 1.925 & 1.724 & 1.541 & 1.357 \\
$-35^{\circ} \mathrm{C}<T \leq-30^{\circ} \mathrm{C}$ & 2.051 & 1.900 & 1.735 & 1.584 & 1.434 \\
$-40^{\circ} \mathrm{C}<T \leq-35^{\circ} \mathrm{C}$ & 2.063 & 1.894 & 1.708 & 1.539 & 1.370 \\
$-45^{\circ} \mathrm{C}<T \leq-40^{\circ} \mathrm{C}$ & 2.055 & 1.885 & 1.698 & 1.528 & 1.358 \\
$-50^{\circ} \mathrm{C}<T \leq-45^{\circ} \mathrm{C}$ & 1.943 & 1.828 & 1.701 & 1.586 & 1.470 \\
$-55^{\circ} \mathrm{C}<T \leq-50^{\circ} \mathrm{C}$ & 1.869 & 1.808 & 1.740 & 1.679 & 1.618 \\
$-60^{\circ} \mathrm{C}<T \leq-55^{\circ} \mathrm{C}$ & 1.760 & 1.753 & 1.746 & - & - \\
$-65^{\circ} \mathrm{C}<T \leq-60^{\circ} \mathrm{C}$ & 1.754 & 1.561 & 1.350 & - & - \\
\hline Mean $\delta$ & 1.959 & 1.828 & 1.685 & 1.585 & 1.446 \\
\hline Standard deviation of $\delta$ & 0.135 & 0.114 & 0.128 & 0.056 & 0.097 \\
\hline Mean uncertainty $(\%)$ & 6.233 & \multicolumn{3}{c}{} \\
\hline
\end{tabular}

example, if the ice cloud microphysical properties and processes being calculated are most relevant to the PSD mass moment (i.e., IWC), then the median mass dimension $\left(D_{\mathrm{m}}\right.$; the particle size dividing the PSD mass into equal parts) is the $D_{\mathrm{i}}$. Fortunately, two-moment microphysical schemes in climate models provide such knowledge since the slope parameter $(\lambda)$ of the PSD is predicted. The $m-D$ exponent $\beta$ is generally near 2 for $D>150 \mu \mathrm{m}$ (see Tables 3 and 4) and tends to be $\sim 2.7$ for $D \sim 50 \mu \mathrm{m}$. Thus, $D_{\mathrm{m}}$ can be approximated using an exact expression from Mitchell (1991):

$D_{\mathrm{m}}=\frac{\beta+v+0.67}{\lambda}$,

where it assumes that a gamma function describes the PSD, given as

$N(D)=N_{o} D^{v} \exp (-\lambda D)$,

where $v$ is the PSD dispersion parameter (often assumed to be constant) and $N_{o}$ depends on $N$ or the IWC. Similarly, Tables 5 and 6 show $\delta$ is near 1.7 for $D>150 \mu \mathrm{m}$ and is close to 2.0 for $D \sim 50 \mu \mathrm{m}$. If the PSD area moment is most relevant to model calculations (e.g., ice optical properties), then $D_{\mathrm{i}}$ is the median area dimension $\left(D_{\mathrm{A}}\right)$ :

$D_{\mathrm{A}}=\frac{\delta+v+0.67}{\lambda}$

Moreover, if the PSD radar reflectivity moment is most relevant to model calculations, then $D_{\mathrm{i}}$ is the median radar reflectivity dimension $\left(D_{Z}\right)$ :

$D_{Z}=\frac{2 \beta+v+0.67}{\lambda}$ 
When addressing ice nucleation, either the mean size $(\bar{D})$ or the median number concentration dimension $\left(D_{N}\right)$ may be used:

$D_{N}=\frac{\nu+0.67}{\lambda}$.

Because $\beta$ and $\delta$ vary slowly with respect to $D, D_{\mathrm{i}}$ can be well approximated for a given temperature regime by evaluating $\beta$ and $\delta$ at $D=500 \mu \mathrm{m}$ and then solving for $D_{\mathrm{i}}$. An iterative procedure can yield exact solutions for $\beta, \delta, \alpha, \gamma$, and $D_{\mathrm{i}}$ using the following steps: (a) $\beta, \delta, \alpha$, and $\gamma$ are evaluated at $D=500 \mu \mathrm{m}$ using Eqs. (5) and (6). (b) $D_{\mathrm{i}}$ is calculated as indicated above, along with any PSD properties of interest such as $D_{\mathrm{e}}$ or $V_{\mathrm{m}}$. (c) $\beta, \delta, \alpha$, and $\gamma$ are recalculated based on $D_{\mathrm{i}}$ and the appropriate curve fit. (d) These updated values are then used to recalculate $D_{\mathrm{i}}$, along with any PSD properties of interest. A single iteration yields $D_{\mathrm{A}}, D_{\mathrm{m}}, \delta$, and $\beta$ within $0.5,1.5,0.6$, and $1.9 \%$ of their exact values, respectively. Thus, only one iteration is needed for most applications since changes in $D_{\mathrm{i}}$ are primarily due to changes in $\lambda$.

Calculating $D_{\mathrm{i}}$ is a means of approximating the size range relevant to the ice properties or processes being determined. To calculate $D_{\mathrm{i}}, \lambda$ must be supplied by the cloud resolving model. In the Community Atmosphere Model version 5 (CAM5; Gettelman et al., 2010), $\lambda$ is obtained from the ratio IWC / $N$ where the PSD is expressed as a gamma function, as shown by Eq. (8). Solving for $\lambda$,

$\lambda=\left[\frac{\alpha \Gamma(\beta+v+1) N}{\Gamma(v+1) \operatorname{IWC}}\right]^{\frac{1}{\beta}}$,

where $\Gamma$ denotes the gamma function. Although the dependence of $\lambda$ on $\alpha$ and $\beta$ complicates matters, Eq. (12) can be solved iteratively using the following steps: (a) $\lambda$ is initially estimated by evaluating $\alpha, \beta, \gamma$, and $\delta$ at $D=500 \mu \mathrm{m}$ for a given $N$ and IWC using Eqs. (5), (6), and (12). (b) These values of $\lambda, \delta$ and $\beta$ are then used to calculate $D_{\mathrm{i}}$ as described above. (c) The revised $D_{\mathrm{i}}$ value is then used in Eqs. (5) and (6) to generate revised values for $\beta, \alpha, \delta$, and $\gamma$, which are then used in Eq. (12) to revise $\lambda$. (d) This revised $\lambda$ revises $D_{\mathrm{i}}$, and the cycle repeats but entering at step (c); subsequent iteration involves only steps (c) and (d). For solving Eq. (12), $D_{\mathrm{i}}$ is equal to $D_{\mathrm{m}}$ since the derivation of Eq. (12) reveals that $\alpha$ and $\beta$ are associated with the IWC PSD moment. Again, this approach is feasible since changes in $\lambda$ primarily result from changes in $N$ and IWC. The $\lambda$ produced from a single iteration has an error of $1.2 \%$ when $\bar{D}=14 \mu \mathrm{m}$ (in the size regime where errors are greatest).

Alternatively, $\lambda$ can be obtained using a look-up table (LUT) that relates $\lambda$ to $N$ and IWC for all relevant combinations of $\alpha$ and $\beta$. The LUT can be produced through the iterative process described above.
While the resulting $m-D$ or $A-D$ power law is only valid over a limited size range, since it is centered on $D_{\mathrm{i}}$, it should be sufficiently accurate for calculating various ice microphysical properties (some used to calculate optical properties) such as IWC, $D_{\mathrm{e}}, V_{\mathrm{m}}, Z$, or ice nucleation rates. This also allows many microphysical rates and quantities to be represented analytically in a simple way since power law expressions are easily integrated over the PSD and are thus compatible with climate model architectures. In this way, the $m-D$ and $A-D$ power laws become a function of the $\lambda$. This should significantly improve the accuracy of predicting cloud microphysical and radiative properties and cloud radiative forcing in general, as well as unify microphysical and radiative processes under a common treatment of ice particle area and mass. It is noteworthy that a common data set is used to derive these $m-D$ and $A-D$ expressions, making them self-consistent (generally not achieved in past studies).

\subsection{Impact on calculations of ice particle $N$, $D_{\mathrm{e}}$, and $V_{\mathrm{m}}$}

First in this subsection, these quantities are calculated in the standard way, assuming constant values of $\alpha, \beta, \gamma$, and $\delta$, and then they are calculated using the methodology explained in Sect. 6.1, where $\alpha, \beta, \gamma$, and $\delta$ exhibit a weak dependence on $D$. An exponential PSD is assumed $(v=0)$, and $\alpha, \beta, \gamma$, and $\delta$ are based on the warmest temperature regime $\left(-40^{\circ} \mathrm{C}<T \leq-20^{\circ} \mathrm{C}\right)$.

$N$ can be calculated by manipulating Eq. (12). Figure 12 shows the calculation of $N$ as a function of the $\bar{D}$ for constant $\alpha$ and $\beta$ (black line), variable $\alpha$ and $\beta$ (blue curve), and $\alpha$ and $\beta$ based on C2013 (purple line). Note that $\bar{D}=(v+1) / \lambda$. Also shown is the dependence of $N$ on $\bar{D}$ when the CAM5 values of $\alpha$ and $\beta$ for cloud ice are used (CAM5 assumes ice spheres having a density of $0.5 \mathrm{~g} \mathrm{~cm}^{-3}$ ). The differences in $N$ for constant, variable, and $\mathrm{C} 2013 \alpha$ and $\beta$ are within about a factor of 2, and the discontinuity in the $\mathrm{C} 2013$ curve is due to an abrupt change in the $m-D$ expression at $D=70 \mu \mathrm{m}$. This discontinuity highlights the drawback of using multiple $m$ $D$ or $A-D$ power laws in climate models and the need for a single $m-D$ or $A-D$ curve fit. There is a large underestimation for $N$ (relative to other curves shown) calculated using the CAM5 values of $\alpha$ and $\beta$. This underscores the danger of representing ice particles as spheres in climate models.

Based on Foot (1988) and Mitchell (2002), $D_{\mathrm{e}}$ is defined as

$D_{\mathrm{e}}=\frac{3 \mathrm{IWC}}{2 \rho_{\mathrm{i}} A_{\mathrm{t}}}$,

where $A_{\mathrm{t}}$ is the total PSD projected area and $\rho_{\mathrm{i}}$ is bulk density of ice. Most climate models use $D_{\mathrm{e}}$ to predict ice cloud optical properties. Assuming an analytical PSD given by Eq. (8) and applying Eqs. (2) and (3), $D_{\mathrm{e}}$ is given as 


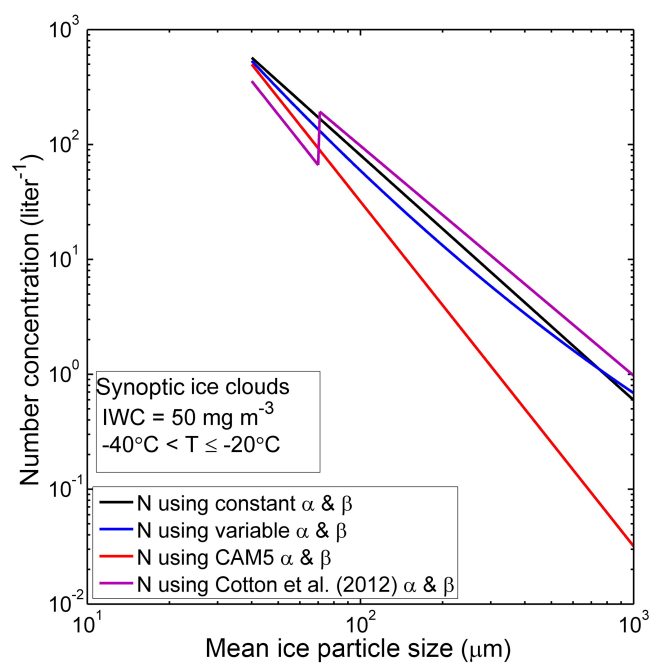

Figure 12. Dependence of the ice particle $N$ on $\bar{D}$ using the four methods indicated for determining $\alpha$ and $\beta$. The black and blue curves use the $m-D$ curve fit based on Table 1 for the indicated temperature range, with the black curve $\alpha$ and $\beta$ evaluated at $D=500 \mu \mathrm{m}$.

$D_{\mathrm{e}}=\frac{3 \alpha \Gamma(\beta+v+1)}{2 \rho_{i} \gamma \Gamma(\delta+v+1)} \lambda^{\delta-\beta}$.

From Eq. (14), it is clear that $D_{\mathrm{e}}$ strongly depends on $\alpha, \beta$, $\gamma$, and $\delta$. When calculating $D_{\mathrm{e}}$ for variable values of $\alpha, \beta$, $\gamma$, and $\delta, \alpha$, and $\beta$ were determined from $D_{\mathrm{m}}$ (associated with IWC) while $\gamma$ and $\delta$ were determined from $D_{\mathrm{A}}$ (associated with PSD projected area). Figure 13 shows that significant differences exist between $D_{\mathrm{e}}$ based on constant and variable values of $\alpha, \beta, \gamma$, and $\delta$, especially at $\bar{D}<50 \mu \mathrm{m}$ and $\bar{D}>500 \mu \mathrm{m}$; and at these size ranges, $D_{\mathrm{e}}$ based on constant $\alpha, \beta, \gamma$, and $\delta$ is greater than $D_{\mathrm{e}}$ based on variable ones. Also shown is $D_{\mathrm{e}}$ based on $\alpha, \beta, \gamma$, and $\delta$ values assumed for cloud ice in CAM5, which shows dramatic overestimation compared to two other methods, and these changes are greatest when $\bar{D}>100 \mu \mathrm{m}$.

$V$ is another property that depends on the $m / A$ ratio. The method of Heymsfield and Westbrook (2010) is sometimes used to predict $V$ where $V$ is predicted from the Best number $(X)$, defined as

$X=\frac{\rho_{\text {air }}}{\eta^{2}} \frac{8 m g}{\pi A_{\mathrm{r}}^{0.5}}$,

where $\rho_{\text {air }}$ is the density of air, $\eta$ is the dynamic viscosity, and $g$ is the gravitational constant. The PSD $V_{\mathrm{m}}$ was calculated from $D_{\mathrm{m}}$ using the Heymsfield-Westbrook scheme, where $\alpha$, $\beta, \gamma$, and $\delta$ may be fixed or variable. Figure 14 denotes that considerable differences can exist for $V_{\mathrm{m}}$ at $\bar{D}<20 \mu \mathrm{m}$ and $\bar{D}>500 \mu \mathrm{m}$, depending on whether $V_{\mathrm{m}}$ was based on fixed

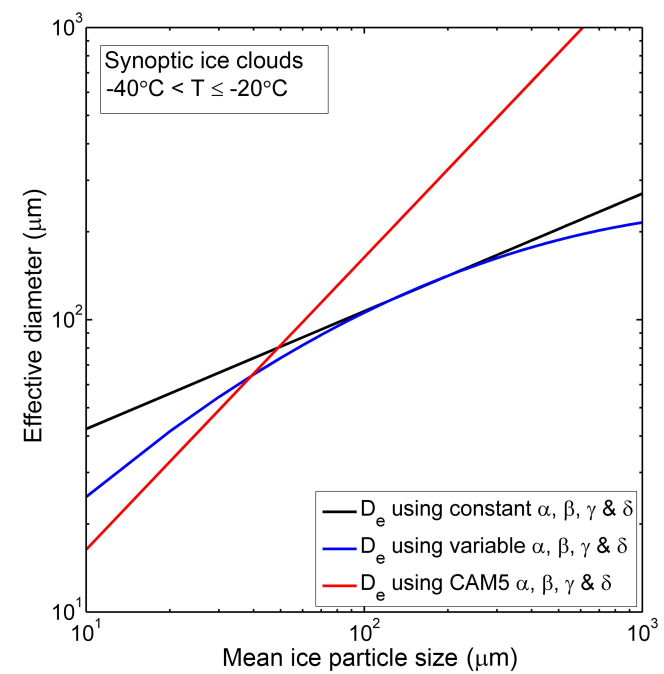

Figure 13. Dependence of the $D_{\mathrm{e}}$ on $\bar{D}$ using the three methods indicated for determining $\alpha, \beta, \gamma$, and $\delta$. The black and blue curves use the $m-D$ curve fit based on Table 1 and $A-D$ curve fit based on Table 2 for the indicated temperature range, with the black curve $\alpha, \beta, \gamma$, and $\delta$ evaluated at $D=500 \mu \mathrm{m}$.

or variable values of $\alpha, \beta, \gamma$, and $\delta$. Note that $V_{\mathrm{m}}$ based on constant $\alpha, \beta, \gamma$, and $\delta$ is greater than $V_{\mathrm{m}}$ based on variable ones. In addition, $V_{\mathrm{m}}$ was calculated for the fixed values of $\alpha, \beta, \gamma$, and $\delta$ used in CAM5 for cloud ice. In this case, errors in $V_{\mathrm{m}}$ are much greater (with greatest error seen at $\bar{D}>100 \mu \mathrm{m}$ ), again underscoring potential errors that may result by assuming spheres for ice particles.

\section{Conclusions and summary}

The findings presented here constitute a fundamental shift in our way of representing ice particle mass and projected area in atmospheric models and remote sensing algorithms. Rather than having a multitude of $m-D$ and $A-D$ power law expressions for different ice particle shapes, size ranges, temperature regimes, and/or cloud types, several second-order polynomial fits may suffice for ice clouds at different temperature intervals, perhaps only three for each cloud type (see Fig. 4). From these fit equations, any number of $m-D$ and $A$ $D$ power law expressions can be derived to address the ice particle size range of interest.

The $m-D$ curves developed here appear representative of ice particle masses in ice clouds for $T<-20^{\circ} \mathrm{C}$ since they are in good conformity with $m-D$ power laws developed under similar conditions in recent studies as shown in Figs. 8 and 9. Moreover, they conform well to the masses of ice particle shapes commonly found between -20 and $-40^{\circ} \mathrm{C}$, although measured at ground level during SCPP. 
Ice particle projected area was directly measured using the 2D-S and CPI probes during SPARTICUS. The mass of ice particles originating between -20 and $-40{ }^{\circ} \mathrm{C}$ was directly measured for synoptic ice clouds (i.e., SCPP data); otherwise it was calculated from projected area using the BL2006 $m$ - $A$ relationship for $D>200 \mu \mathrm{m}$ or it was calculated from CPI measurements for $D<100 \mu \mathrm{m}$ using our new method (see Appendix B). Since the SCPP $m-D$ measurements were consistent with the 2D-S $m$ - $D$ estimates between -20 and $-40^{\circ} \mathrm{C}$, the resulting $m-D$ and $A-D$ expressions were essentially developed from the same SPARTICUS data set, containing 158 PSDs for synoptic ice clouds and 107 PSDs for anvil ice clouds. Therefore, the $m-D$ and $A-D$ expressions should be self-consistent, as confirmed in Fig. 7. Three temperature regimes were defined such that, within a given regime, the variance in $m$ or $A$ for a given $D$ was minimal, and a couple of $m-D$ and $A-D$ second-order polynomial fits was determined for each temperature regime and for each cloud type: synoptic and anvil. The $m-D$ and $A-D$ expressions for synoptic and anvil ice clouds were very similar within each temperature regime.

A methodology was developed for extracting $m-D$ and $A$ $D$ power laws from these second-order polynomial fits that are appropriate to the ice particle size range (e.g., PSD moments) of interest. In this way, these polynomial fits can easily be applied to cloud and climate models without much interference in model architecture (since many of these models have their cloud microphysics formulated in terms of these $m-D$ and $A-D$ power laws). The prefactor and exponent for these power laws vary slowly with $D$, and significantly greater accuracy can be achieved when calculating cloud properties from these fit equations relative to power laws having a fixed prefactor and exponent. Treating ice particles as spheres in cloud models was shown to produce large microphysical errors.

Remote sensing algorithms that retrieve cloud properties strongly depend on $m-D$ and $A-D$ power laws, with confidence levels for the retrieved cloud property often largely

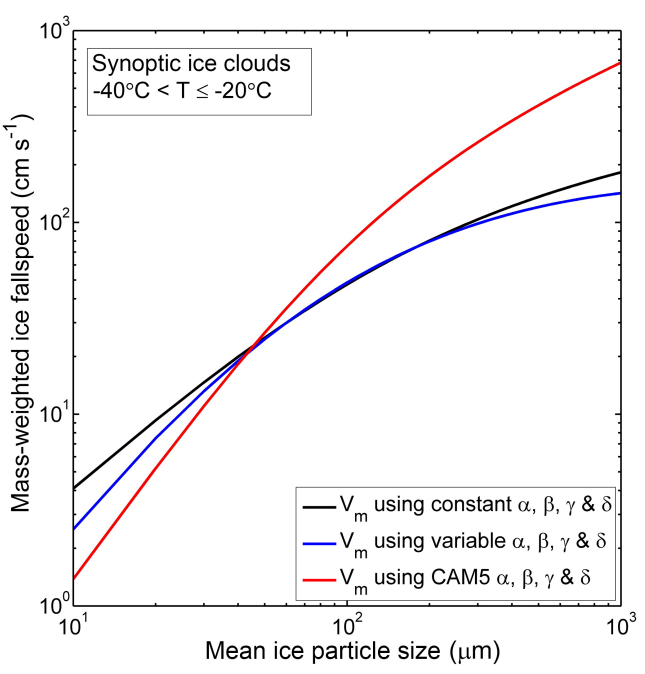

Figure 14. Same as Fig. 13 but for the dependence of $V_{\mathrm{m}}$ on $\bar{D}$.

determined by the uncertainty associated with these power laws (e.g., Delanoe and Hogan, 2010). This study has quantified these uncertainties and has found that most of the uncertainty lies in the prefactor. Application of these $m-D$ and $A-D$ uncertainties to the remote sensing of ice cloud properties will likely improve the confidence of such retrievals. This study was focused only on midlatitude continental ice clouds and not on marine anvil or synoptic cirrus, orographic cirrus, and/or Arctic ice clouds. Application of BL2006 (which is based on a subset of SCPP data from midlatitude continental clouds) to tropical anvil clouds produced IWC with only $\sim 18 \%$ difference compared to measured bulk IWC (Lawson et al., 2010). However, use of BL2006 in arctic mixed-phase clouds leads to IWC $\sim 100 \%$ larger than measured bulk IWC (Jackson et al., 2012). Additional research is required to apply and test the approach introduced in this study in different environments. 


\section{Appendix A: Comparison between M1 and M7 methods for 2D-S probe}

There are various methods to process 2D-S data, such as M1, M2, M4, and M7 methods (Lawson, 2011). Explanation and comparison of all these methods are beyond the scope of this paper. The M1 method was originally used in this study, but the newly developed M7 method replaced the M1 method for two main reasons. First, the M1 and M7 methods differ on the measurement of particle dimensions, as is shown in Fig. A1. Two ice particles with different shapes are shown to give the reader an idea of how the different length scales (L1, L4, and MaxLength) for different ice particle shapes are measured and calculated by the 2D-S and its respective software. The horizontal direction represents the direction of particle travel into the 2D-S probe and is sometimes referred to as the time dimension. The M1 method calculates maximum dimension as the dimension along the direction of travel (length scale L1), whereas the M7 method calculates the maximum dimension of the particle 2-D image as the diameter of a circumscribed circle around the particle (length scale MaxLength). Therefore, M7 method provides a more realistic measurement of maximum dimension, compared to many other studies that used L1. Note that length scale L4 in Fig. A1 is not the particle "height" range (projected along the vertical photodiode array) during its entire transit time through the sample volume; rather it is a measure of particle width at a given instant. Moreover, L4 is the maximum value of all these time slices (i.e., widths) measured.

Second, the M1 and M7 methods are distinct in the treatment of particles that intersect the edges of the 2D-S field of view. Using the M1 method, all particles are included in the measurement of projected area and number concentration, even particles that intersect the edges of the 2D-S field of view, and in those cases their maximum dimension and projected area are approximated. When using the M7 method, only particles that are completely inside the 2D-S field of view ("all-in" particles) are included. This provides an accurate measurement of projected area and maximum dimension for all particles. Although the sample volume decreases by using M7 method, such a decrease is not significant. Figures $\mathrm{S} 1$ and $\mathrm{S} 3$ show number concentration and area concentration as functions of maximum dimension for cases of synoptic and anvil cirrus clouds, respectively. It is seen that the M1 and M7 methods agree well for both number concentration and area concentration, with a larger difference between the M1 and M7 methods observed for larger particles $(D>300 \mu \mathrm{m})$. Moreover, the comparison of the M1 and M7 methods for the PSD number concentration and extinction is displayed in Figs. S2 and S4. The difference in PSD projected area (i.e., extinction) between the M1 and M7 methods does not exceed 5 and $13 \%$ for synoptic and anvil cirrus clouds, respectively. In other words, the difference for projected area is more pronounced in anvil than in synoptic cirrus due to slightly larger ice particles in anvil clouds that
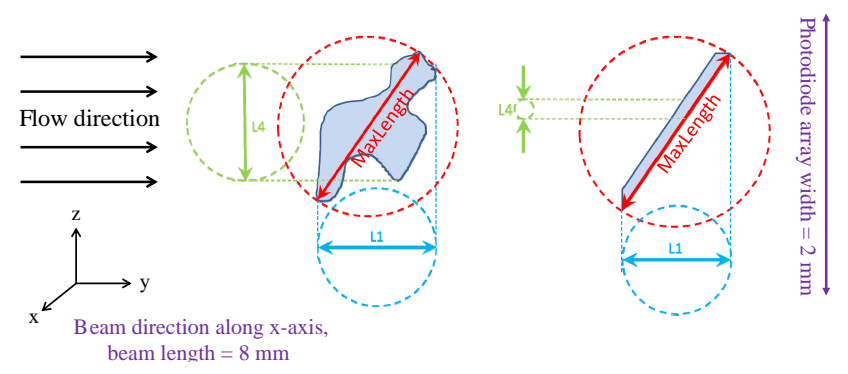

Figure A1. Geometry of dimension measurements showing length scales for the M1 method (L1) and the M7 method (MaxLength) for two different ice particle shapes. Courtesy of Paul Lawson and Sara Lance.

have a greater chance of intersecting the edges of the 2D-S field of view.

\section{Appendix B: Calculation of ice particle mass from CPI measurements of projected area and aspect ratio}

There is no direct measurement of ice particle mass by the CPI probe. Moreover, the BL2006 $m$ - $A$ relationship is based on ice particles larger than $\sim 150 \mu \mathrm{m}$. Therefore, we developed a new method for estimating mass based on CPI measurements of ice particle projected area, length and width. It is assumed that when $10 \mu \mathrm{m}<D<100 \mu \mathrm{m}$, all ice crystals are hexagonal columns. The apparent aspect ratio $(\varepsilon)$, defined as the CPI measured mean length-to-width ratio for a given size interval, is generally between 1 and 2 in this size range and the ice crystals are known to be relatively dense (more mass per maximum dimension), making this shape assumption a reasonable approximation (Korolev and Isaac, 2003; Lawson et al., 2006a; C2013). This is more accurate than assuming ice particles to be spherical.

Figure B1a shows the geometrical features of a hexagonal prism that has eight faces: two basal faces with hexagonal shape and six prism faces with rectangular shape. The axis along the prism face is defined as the $c$ axis and the maximum dimension across the basal face is defined as the $a$ axis. The true aspect ratio $(\zeta)$ of a hexagonal column is defined as $\frac{c}{a}$ (Lamb and Verlinde, 2011; Pruppacher and Klett, 1998). Since the CPI provides 2-D images, $\zeta$ and $\varepsilon$ can be different due to crystal orientation. As far as we know, there is no preferred orientation for small ice crystals entering the CPI probe sample volume. Therefore, we assume random orientation and develop a method to estimate $\zeta$ from $\varepsilon$ as described here.

Consider three planes in the 3-D space: one plane orthogonal to the direction of view or beam direction (hereafter called P1; Fig. B1a), and two planes orthogonal to the first plane in alignment with the direction of view (hereafter called $\mathrm{P} 2$ and $\mathrm{P} 3$ ). When the $c$ axis is parallel to $\mathrm{P} 1$, all orientations of a hexagonal column yield the projected area equal 
(a)

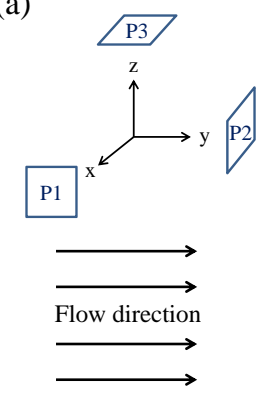

(b)

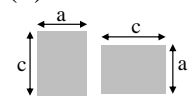

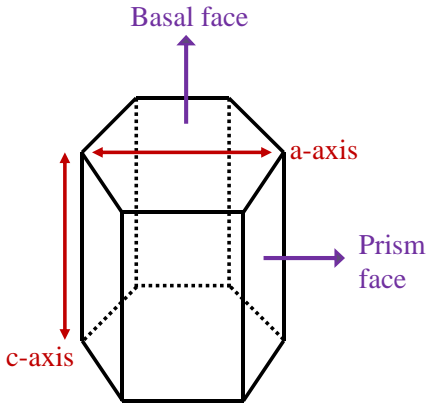

(c)

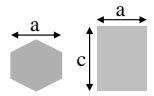

(d)

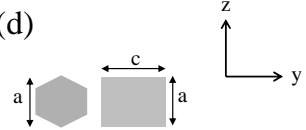

Figure B1. (a) Three-dimensional geometry of a hexagonal prism, representative of small ice crystals. Assuming that the direction of view (beam direction) is along the $x$ axis, $\mathrm{P} 1$ is orthogonal to $x$ axis, $\mathrm{P} 2$ is orthogonal to $y$ axis, and $\mathrm{P} 3$ is orthogonal to $z$ axis. Also shown is the projection of a hexagonal prism for three extremes, when its $c$ axis is parallel to (b) P1, (c) P2, and (d) P3. See text for the definition of various symbols.

to the area of the prism face $\left(A_{\mathrm{p}, \max }\right)$, as shown in Fig. B1b. However, when the $c$ axis is parallel to $\mathrm{P} 2$ or $\mathrm{P} 3$, the maximum and minimum projected areas correspond to $A_{\mathrm{p}, \max }$ and the area of the basal face $\left(A_{\mathrm{b}, \max }\right)$, respectively (Fig. B1c and d). Therefore, for both P2 and P3, the average hexagonal column projected area corresponds to the average projected area of these two extremes: $\left(A_{\mathrm{p}, \max }+A_{\mathrm{b}, \max }\right) / 2$. Thus, the average projected area for all orientations $\langle A\rangle$ can be estimated as the average of the mean projected area in three planes:

$$
\begin{aligned}
\langle A\rangle & \approx \frac{1}{3}\left(A_{\mathrm{p}, \max }+\frac{A_{\mathrm{p}, \max }+A_{\mathrm{b}, \text { max }}}{2}\right. \\
& \left.+\frac{A_{\mathrm{p}, \max }+A_{\mathrm{b}, \max }}{2}\right) .
\end{aligned}
$$

Since $A_{\mathrm{p}, \max }$ is equal to ac (area of rectangle) and $A_{\mathrm{b}, \max }$ is equal to $3^{\frac{3}{2}} a^{2} / 8$ (area of hexagon):

$\langle A\rangle \approx \frac{1}{3}\left(2 a c+\frac{3^{\frac{3}{2}} a^{2}}{8}\right)$.

Noting that $c=\zeta a$, we can write

$\langle A\rangle \approx \frac{1}{3}\left(2 \zeta a^{2}+\frac{3^{\frac{3}{2}} a^{2}}{8}\right)$.

Expanding on the insight from Eq. (B1), $\zeta$ can be estimated from $\varepsilon$. In the P1 plane, $\varepsilon$ is equal to $\zeta$. However,

for P2 and P3, there are two extremes: $\varepsilon=\zeta$ when $A=$ $A_{\mathrm{p}, \max }$, and $\varepsilon=1$ when $A=A_{\mathrm{b}, \max }$. So, the crystal orientation and apparent aspect ratio representing $\mathrm{P} 2$ and $\mathrm{P} 3$ will be the average of these two extremes $(\zeta+1) / 2$. The overall value for $\varepsilon$ should equal the average apparent aspect ratio corresponding to all three planes. Therefore, $\varepsilon$ is equal to $[\zeta+(\zeta+1) / 2+(\zeta+1) / 2] / 3$, and we can write

$\varepsilon=\frac{1}{3}(2 \zeta+1)$

Solving for $\zeta$ from Eq. (B4):

$\zeta=\frac{(3 \varepsilon-1)}{2}$,

Let $A_{\mathrm{cpi}}$ be the CPI measurement of projected area. Then, Eq. (B3) represents $A_{\text {cpi }}$, and it can be used to estimate $a$ :

$a \approx\left(\frac{3 A_{\mathrm{cpi}}}{2 \zeta+\frac{3^{\frac{3}{2}}}{8}}\right)^{\frac{1}{2}}$.

Volume of a hexagonal column $\left(V_{\mathrm{h}}\right)$ is defined as

$V_{\mathrm{h}}=\left(\frac{3^{\frac{3}{2}}}{8}\right) a^{2} c$.

The mass of a hexagonal column $(m)$ is equal to $\rho_{i} V_{\mathrm{h}}$, where $\rho_{\mathrm{i}}$ is bulk density of ice and is equal to $0.917 \mathrm{~g} \mathrm{~cm}^{-3}$. Therefore, the ice particle mass can be estimated from $a$ and $\zeta$ as

$m_{\mathrm{cpi}}=\rho_{\mathrm{i}}\left(\frac{3^{\frac{3}{2}}}{8}\right) a^{3} \zeta$.

Since $\zeta$ and $a$ are calculated from Eqs. (B5) and (B6), respectively, $m_{\mathrm{cpi}}$ is estimated from $A_{\mathrm{cpi}}$ and $\varepsilon$.

One benefit of the hexagonal column assumption is consideration of ice particle aspect ratio. The spherical ice assumption means that the aspect ratio is unity. Assuming that ice particles are spherical, their mass can be calculated as a function of projected area (e.g., $m_{\text {sphere }}=\rho_{\mathrm{i}} \frac{4}{3 \sqrt{\pi}} A_{\text {sphere }}^{3 / 2}$ ). We calculated the percent difference of mass between the spherical and hexagonal column assumptions (where column aspect ratio $=1.0$ ), and this value is $\sim 4 \%$. 


\section{Appendix C: List of symbols}

a maximum dimension across the basal face of a hexagonal crystal

$a_{v} \quad$ prefactor in fall speed-dimension power law

$A \quad$ projected area

$\langle A\rangle \quad$ average projected area of a hexagonal crystal for all orientations

$A_{\mathrm{b}, \max }$ area of the basal face of a hexagonal crystal

$A_{\mathrm{p}, \max }$

$A_{\mathrm{r}}$ area of the prism face of a hexagonal crystal

area ratio

$A_{\mathrm{t}} \quad$ total PSD projected area

$b_{v} \quad$ exponent in fall speed-dimension power law

$c \quad$ length along the prism face of a hexagonal crystal

$D \quad$ maximum dimension of ice particle

$D_{o} \quad$ characteristic dimension of the ice PSD

$\bar{D} \quad$ mean maximum dimension of a PSD

$D_{\mathrm{A}} \quad$ median area dimension

$D_{\mathrm{e}} \quad$ effective diameter

$D_{\mathrm{i}} \quad$ dimension of interest

$D_{\mathrm{m}} \quad$ median mass dimension

$D_{N} \quad$ number concentration dimension

$D_{Z} \quad$ reflectivity dimension

$g \quad$ gravitational constant

IWC ice water content

$m \quad$ mass of ice particle

$N \quad$ number concentration

$N_{o} \quad$ prefactor of a gamma PSD

PSD particle size distribution

$R \quad$ relative ratio of mass to area

$R^{2} \quad$ coefficient of determination

$T$ temperature

$V \quad$ terminal fall speed of ice particle

$V_{\mathrm{h}} \quad$ volume of a hexagonal crystal

$V_{\mathrm{m}} \quad$ mass-weighted terminal fall speed

$Z \quad$ radar reflectivity

$X \quad$ Best number

$\alpha \quad$ prefactor in mass-dimension power law

$\beta \quad$ exponent in mass-dimension power law

$\gamma \quad$ prefactor in projected area-dimension power law

$\delta \quad$ exponent in projected area-dimension power law

$\Gamma \quad$ gamma function

$\varepsilon \quad$ apparent aspect ratio

$\zeta \quad$ true aspect ratio

$\eta \quad$ dynamic viscosity of air

$\lambda$ slope parameter of a gamma PSD

$v \quad$ dispersion parameter of a gamma PSD

$\sigma \quad$ standard deviation

$\rho_{\text {air }} \quad$ density of air

$\rho_{\mathrm{i}} \quad$ bulk density of ice 


\section{The Supplement related to this article is available online at doi:10.5194/acp-16-4379-2016-supplement.}

Acknowledgements. This research was supported by the Office of Science (BER), US Department of Energy. We are very grateful to Paul Lawson, Sara Lance, Sarah Woods, Ted Fisher, and Qixo Mo for processing the SPARTICUS 2D-S and CPI data in a manner that best served the needs of this study. We are also grateful to Brad Baker for providing us with the measurements of ice particle projected area that were used in BL2006. The first author would like to appreciate Office of International Students and Scholars at University of Nevada, Reno, for awarding an international student scholarship for 2 years. Finally, the authors express their gratitude to two anonymous reviewers for their constructive comments that improved the paper. The SCPP data used in this study and associated software are freely available to interested researchers; those interested should contact the second author.

Edited by: C. Hoose

\section{References}

Avramov, A., Ackerman, A. S., Fridlind, A. M., van Diedenhoven, B., Botta, G., Aydin, K., Verlinde, J., Korolev, A. V., Strapp, J. W., McFarquhar, G. M., Jackson, R., Brooks, S. D., Glen, A., and Wolde, M.: Toward ice formation closure in Arctic mixed-phase boundary layer clouds during ISDAC, J. Geophys. Res.-Atmos., 116, D00T08, doi:10.1029/2011JD015910, 2011.

Bailey, M. P. and Hallett, J.: Growth Rates and Habits of Ice Crystals between $-20^{\circ}$ and $-70^{\circ} \mathrm{C}$, J. Atmos. Sci., 61, 514-544, 2004.

Bailey, M. P. and Hallett, J.: A Comprehensive Habit Diagram for Atmospheric Ice Crystals: Confirmation from the Laboratory, AIRS II, and Other Field Studies, J. Atmos. Sci., 66, 2888-2899, doi:10.1175/2009JAS2883.1, 2009.

Baker, B. and Lawson, R. P.: Improvement in determination of ice water content from two-dimensional particle imagery. Part I: Image-to-mass relationships, J. Appl. Meteorol. Clim., 45, 12821290, doi:10.1175/jam2398.1, 2006a.

Baker, B. A. and Lawson, R. P.: In Situ Observations of the Microphysical Properties of Wave, Cirrus, and Anvil Clouds. Part I: Wave Clouds, J. Atmos. Sci., 63, 3160-3185, 2006b.

Baran, A. J.: From the single-scattering properties of ice crystals to climate prediction: A way forward, Atmos. Res., 112, 45-69, doi:10.1016/j.atmosres.2012.04.010, 2012.

Brown, P. R. A. and Francis, P. N.: Improved measurements of the ice water content in cirrus using a total-water probe, J. Atmos. Ocean. Tech., 12, 410-414, doi:10.1175/15200426(1995)012<0410:imotiw>2.0.co;2, 1995.

Cotton, R. J., Field, P. R., Ulanowski, Z., Kaye, P. H., Hirst, E., Greenaway, R. S., Crawford, I., Crosier, J., and Dorsey, J.: The effective density of small ice particles obtained from in situ aircraft observations of mid-latitude cirrus, Q. J. Roy. Meteor. Soc., 139, 1923-1934, doi:10.1002/qj.2058, 2013.
Delanoe, J. and Hogan, R. J.: Combined CloudSat-CALIPSOMODIS retrievals of the properties of ice clouds, J. Geophys. Res.-Atmos., 115, D00h29, doi:10.1029/2009jd012346, 2010.

Eidhammer, T., Morrison, H., Mitchell, D. L., Gettelman, A., and Erfani, E.: Improvements in the Community Atmosphere Model (CAM5) microphysics using a consistent representation of ice particle properties, J. Climate, accepted, 2016.

Fontaine, E., Schwarzenboeck, A., Delanoë, J., Wobrock, W., Leroy, D., Dupuy, R., Gourbeyre, C., and Protat, A.: Constraining mass-diameter relations from hydrometeor images and cloud radar reflectivities in tropical continental and oceanic convective anvils, Atmos. Chem. Phys., 14, 11367-11392, doi:10.5194/acp14-11367-2014, 2014.

Foot, J. S.: Some observations of the optical properties of clouds. Part II: Cirrus, Q. J. Roy. Meteor. Soc., 114, 145-164, 1988.

$\mathrm{Fu}, \mathrm{Q}$.: An accurate parameterization of the solar radiative properties of cirrus clouds for climate models, J. Climate, 9, 20582082, doi:10.1175/1520-0442(1996)009<2058:aapots>2.0.co;2, 1996.

Fu, Q., Yang, P., and Sun, W. B.: An accurate parameterization of the infrared radiative properties of cirrus clouds for climate models, J. Climate, 11, 2223-2237, doi:10.1175/15200442(1998)011<2223:aapoti>2.0.co;2, 1998.

Gettelman, A., Liu, X., Ghan, S. J., Morrison, H., Park, S., Conley, A. J., Klein, S. A., Boyle, J., Mitchell, D. L., and Li, J. L. F.: Global simulations of ice nucleation and ice supersaturation with an improved cloud scheme in the Community Atmosphere Model, J. Geophys. Res.-Atmos., 115, D18216, doi:10.1029/2009jd013797, 2010.

Heymsfield, A. J. and Westbrook, C. D.: Advances in the Estimation of Ice Particle Fall Speeds Using Laboratory and Field Measurements, J. Atmos. Sci., 67, 2469-2482, doi:10.1175/2010jas3379.1, 2010.

Heymsfield, A. J., Lewis, S., Bansemer, A., Iaquinta, J., Miloshevich, L. M., Kajikawa, M., Twohy, C., and Poellot, M. R.: A general approach for deriving the properties of cirrus and stratiform ice cloud particles, J. Atmos. Sci., 59, 3-29, doi:10.1175/15200469(2002)059<0003:agafdt>2.0.co;2, 2002.

Heymsfield, A. J., Bansemer, A., Schmitt, C., Twohy, C., and Poellot, M. R.: Effective ice particle densities derived from aircraft data, J. Atmos. Sci., 61, 982-1003, doi:10.1175/15200469(2004)061<0982:eipddf>2.0.co;2, 2004.

Heymsfield, A. J., Bansemer, A., and Twohy, C. H.: Refinements to ice particle mass dimensional and terminal velocity relationships for ice clouds. Part I: Temperature dependence, J. Atmos. Sci., 64, 1047-1067, doi:10.1175/jas3890.1, 2007.

Heymsfield, A. J., Schmitt, C., Bansemer, A., and Twohy, C. H.: Improved Representation of Ice Particle Masses Based on Observations in Natural Clouds, J. Atmos. Sci., 67, 3303-3318, doi:10.1175/2010jas3507.1, 2010.

Jackson, R. C., McFarquhar, G. M., Korolev, A. V., Earle, M. E., Liu, P. S., Lawson, R. P., Brooks, S., Wolde, M., Laskin, A., and Freer, M.: The dependence of ice microphysics on aerosol concentration in arctic mixed-phase stratus clouds during ISDAC and M-PACE, J. Geophys. Res.-Atmos., 117, D15207, doi:10.1029/2012JD017668, 2012.

Jensen, E. J., Lawson, R. P., Bergman, J. W., Pfister, L., Bui, T. P., and Schmitt, C. G.: Physical processes controlling ice concen- 
trations in synoptically forced, midlatitude cirrus, J. Geophys. Res.-Atmos., 118, 5348-5360, doi:10.1002/jgrd.50421, 2013.

Korolev, A.: Reconstruction of the sizes of spherical particles from their shadow images. Part I: Theoretical considerations, J. Atmos. Ocean. Tech., 24, 376-389, doi:10.1175/jtech1980.1, 2007.

Korolev, A. and Isaac, G.: Roundness and aspect ratio of particles in ice clouds, J. Atmos. Sci., 60, 1795-1808, doi:10.1175/15200469(2003)060<1795:raarop>2.0.co;2, 2003.

Korolev, A., Strapp, J. W., and Isaac, G. A.: Evaluation of the accuracy of PMS Optical Array Probes, J. Atmos. Ocean. Tech., 15, 708-720, doi:10.1175/15200426(1998)015<0708:eotaop>2.0.co;2, 1998.

Lamb, D. and Verlinde, J.: Physics and Chemistry of Clouds, Cambridge University Press, New York, NY, USA, 2011.

Lawson, R. P.: Effects of ice particles shattering on the 2D-S probe, Atmos. Meas. Tech., 4, 1361-1381, doi:10.5194/amt-4-13612011, 2011.

Lawson, R. P.: Improvement in Determination of Ice Water Content from Two-Dimensional Particle Imagery. Part III: Ice Particles with High $a$ - to $c$-axis Ratio, J. Appl. Meteorol. Clim., submitted, 2016.

Lawson, R. P., Baker, B. A., Schmitt, C. G., and Jensen, T. L.: An overview of microphysical properties of Arctic clouds observed in May and July 1998 during FIRE ACE, J. Geophys. Res.Atmos., 106, 14989-15014, doi:10.1029/2000jd900789, 2001.

Lawson, R. P., O'Connor, D., Zmarzly, P., Weaver, K., Baker, B., Mo, Q., and Jonsson, H.: The 2D-S (Stereo) probe: Design and preliminary tests of a new airborne, high-speed, high-resolution particle Imaging probe, J. Atmos. Ocean. Tech., 23, 1462-1477, doi:10.1175/jtech1927.1, 2006a.

Lawson, R. P., Baker, B. A., Pilson, B., and Mo, Q.: In situ observations of the microphysical properties of wave, cirrus and anvil clouds. Part II: Cirrus clouds, J. Atmos. Sci., 63, 3186-3203, 2006b.

Lawson, R. P., Jensen, E., Mitchell, D. L., Baker, B., Mo, Q., and Pilson, B.: Microphysical and radiative properties of tropical clouds investigated in TC4 and NAMMA, J. Geophys. Res.Atmos., 115, D00j08, doi:10.1029/2009jd013017, 2010.

Locatelli, J. d. and Hobbs, P. V.: Fall speeds and masses of solid precipitation particles, J. Geophys. Res., 79, 2185-2197, doi:10.1029/JC079i015p02185, 1974.

Mace, J., Jensen, E., McFarquhar, G., Comstock, J., Ackerman, T., Mitchell, D., Liu, X., and Garrett, T.: SPARTICUS: Small Particles in Cirrus, Science and Operations Plan, Tech. Rep., DOE/SC-ARM-10-003, The Atmospheric Radiation Measurement Program, US Department of Energy, available at: https://www.arm.gov/publications/ programdocs/doe-sc-arm-10-003.pdf (last access: 20 October 2015), 2009.

McFarquhar, G. M., Timlin, M. S., Rauber, R. M., Jewett, B. F., and Grim, J. A.: Vertical variability of cloud hydrometeors in the stratiform region of mesoscale convective systems and bow echoes, Mon. Weather Rev., 135, 3405-3428, doi:10.1175/mwr3444.1, 2007.

McFarquhar, G. M., Um, J., and Jackson, R.: Small Cloud Particle Shapes in Mixed-Phase Clouds, J. Appl. Meteor. Clim., 52, 1277-1293, doi:10.1175/JAMC-D-12-0114.1, 2013.
Mishra, S., Mitchell, D. L., Turner, D. D., and Lawson, R. P.: Parameterization of ice fall speeds in midlatitude cirrus: Results from SPartICus, J. Geophys. Res.-Atmos., 119, 3857-3876, doi:10.1002/2013jd020602, 2014.

Mitchell, D. L.: Evolution of snow-size spectra in cyclonic storms .1. snow growth by vapor-deposition and aggregation, J. Atmos. Sci., 45, 3431-3452, doi:10.1175/15200469(1988)045<3431:eosssi>2.0.co;2, 1988.

Mitchell, D. L.: Evolution of snow-size spectra in cyclonic storms. 2. deviations from the exponential form, J. Atmos. Sci., 48, 1885-1899, doi:10.1175/15200469(1991)048<1885:eosssi>2.0.co;2, 1991.

Mitchell, D. L.: Use of mass- and area-dimensional power laws for determining precipitation particle terminal velocities, J. Atmos. Sci., 53, 1710-1723, doi:10.1175/15200469(1996)053<1710:uomaad>2.0.co;2, 1996.

Mitchell, D. L.: Parameterization of the Mie extinction and absorption coefficients for water clouds, J. Atmos. Sci., 57, 1311-1326, doi:10.1175/1520-0469(2000)057<1311:potmea>2.0.co;2, 2000.

Mitchell, D. L.: Effective diameter in radiation transfer: General definition, applications, and limitations, J. Atmos. Sci., 59, 2330 2346, doi:10.1175/1520-0469(2002)059<2330:edirtg>2.0.co;2, 2002.

Mitchell, D. L., Zhang, R., and Pitter, R. L.: Mass-dimensional relationships for ice particles and the influence of riming on snowfall rates, J. Appl. Meteorol., 29, 153-163, doi:10.1175/15200450(1990)029<0153:mdrfip>2.0.co;2, 1990.

Mitchell, D. L., Baran, A. J., Arnott, W. P., and Schmitt, C.: Testing and comparing the modified anomalous diffraction approximation, J. Atmos. Sci., 63, 2948-2962, doi:10.1175/jas3775.1, 2006.

Mitchell, D. L., Rasch, P., Ivanova, D., McFarquhar, G., and Nousiainen, T.: Impact of small ice crystal assumptions on ice sedimentation rates in cirrus clouds and GCM simulations, Geophys. Res. Lett., 35, L09806, doi:10.1029/2008g1033552, 2008.

Mitchell, D. L., Mishra, S., and Lawson, R. P.: Representing the ice fall speed in climate models: Results from Tropical Composition, Cloud and Climate Coupling (TC4) and the Indirect and SemiDirect Aerosol Campaign (ISDAC), J. Geophys. Res.-Atmos., 116, D00t03, doi:10.1029/2010jd015433, 2011.

Morrison, H. and Gettelman, A.: A new two-moment bulk stratiform cloud microphysics scheme in the community atmosphere model, version 3 (CAM3). Part I: Description and numerical tests, J. Climate, 21, 3642-3659, doi:10.1175/2008jcli2105.1, 2008.

Pruppacher, H. R. and Klett, J. D.: Microphysics of clouds and precipitation: 2nd Edn., Kluwer Academic Publishers, Dordrecht, the Netherlands, 1996.

Sanderson, B. M., Piani, C., Ingram, W. J., Stone, D. A., and Allen, M. R.: Towards constraining climate sensitivity by linear analysis of feedback patterns in thousands of perturbed-physics GCM simulations, Clim. Dynam., 30, 175-190, doi:10.1007/s00382007-0280-7, 2008.

Um, J. and McFarquhar, G. M.: Dependence of the single-scattering properties of small ice crystals on idealized shape models, Atmos. Chem. Phys., 11, 3159-3171, doi:10.5194/acp-11-31592011, 2011. 
Yang, P., Wei, H. L., Huang, H. L., Baum, B. A., Hu, Y. X., Kattawar, G. W., Mishchenko, M. I., and Fu, Q.: Scattering and absorption property database for nonspherical ice particles in the near- through far-infrared spectral region, Appl. Optics, 44, 5512-5523, doi:10.1364/ao.44.005512, 2005.
Zhao, Y., Mace, G. G., and Comstock, J. M.: The Occurrence of Particle Size Distribution Bimodality in Midlatitude Cirrus as Inferred from Ground-Based Remote Sensing Data, J. Atmos. Sci., 68, 1162-1177, doi:10.1175/2010jas3354.1, 2011. 